INRA Prod. Anim., 2011, 24 (5), 447-460

\title{
Production de méthane et interactions microbiennes dans le rumen
}

M. POPOVA, D.P. MORGAVI, M. DOREAU, C. MARTIN

INRA, UR1213 Herbivores, F-63122 Saint-Genès-Champanelle, France

Courriel : milka.popova@clermont.inra.fr

La production de méthane dans le rumen est contrôlée par l'activité de l'écosystème microbien du rumen, et en particulier des méthanogènes, une communauté encore mal connue. Cet article présente comment les interactions entre populations microbiennes modulent la production de méthane, ainsi que les principales perspectives pour la maîtriser en agissant sur l'écosystème microbien.

Bien que le méthane $\left(\mathrm{CH}_{4}\right)$ soit un produit naturel des fermentations ruminales, sa production représente une perte énergétique de l'ordre de 2 à $12 \%$ de l'énergie ingérée par l'animal (Johnson et Johnson 1995). Il est rejeté dans l'atmosphère essentiellement par voie orale $(95 \%)$ au cours d'éructations régulières ou par les poumons, après passage dans le sang. A l'échelle de la ferme, la contribution du $\mathrm{CH}_{4}$ aux émissions de gaz à effet de serre est comprise entre 40 et $60 \%$; le $\mathrm{CH}_{4}$ d'origine entérique en représente $80 \%$ et les $20 \%$ restants proviennent des effluents d'élevage (Gill et al 2010). Les émissions totales annuelles de $\mathrm{CH}_{4}$ entérique par les animaux d'élevage en France en 2007 s'élevaient à 1,4 million de tonnes avec une contribution des bovins de $90 \%$ (Vermorel et al 2008). Les vaches (laitières et allaitantes) et les mâles reproducteurs représentent à eux seuls $58 \%$ des émissions totales annuelles, suivis par les bovins à l'engraissement $(33 \%)$, la part des ovins, caprins, équins et porcins étant mineure (Vermorel et al 2008). La réduction des émissions de $\mathrm{CH}_{4}$ par les ruminants présente ainsi des intérêts nutritionnels pour l'animal et environnementaux.

Le $\mathrm{CH}_{4}$ est formé dans le rumen quand l'hydrogène $\left(\mathrm{H}_{2}\right)$, libéré par les microorganismes fermentaires (bactéries, champignons et protozoaires), est utilisé par d'autres microorganismes, les Archaea méthanogènes, dans la réduction du dioxyde de carbone $\left(\mathrm{CO}_{2}\right)$. En tant qu'uniques producteurs de $\mathrm{CH}_{4}$, les Archaea méthanogènes du rumen ont fait l'objet d'un certain nombre d'études (Janssen et Kirs 2008). Cependant, comme pour tout écosystème complexe, il est important de considérer les différentes interactions existantes entre microorganismes et environnement (les conditions physico-chimiques du rumen et l'animal hôte dans ce cas précis) d'une part, et entre les différentes populations microbiennes (symbiose, prédation, compétition) d'autre part. Dans ce contexte, concentrer les recherches exclusivement sur les producteurs directs de $\mathrm{CH}_{4}$, en les isolants de leur environnement naturel, peut conduire à de mauvaises interprétations en ce qui concerne la régulation de la production de $\mathrm{CH}_{4}$ dans l'écosystème ruminal. Un nombre restreint d'études a cherché à relier au sein d'un même essai la production de $\mathrm{CH}_{4}$ et l'ensemble des mécanismes microbiens qu'elle implique; un nombre encore plus faible de ces études a été réalisé in vivo.

La production de $\mathrm{CH}_{4}$ dans le rumen dépend de deux facteurs d'égale importance, mais régulés autant l'un que l'autre par les concentrations en $\mathrm{H}_{2}$, la dynamique et l'activité de la population méthanogène et la thermodynamique des fermentations ruminales (Janssen 2010). L'objectif de cet article est de récapituler les réponses microbiennes aux différentes stratégies utilisées pour diminuer la méthanogenèse ruminale; une attention particulière sera portée sur l'utilisation de l' $\mathrm{H}_{2}$ et les effets sur les Archaea méthanogènes.

\section{1 / L'écosystème microbien ruminal et la production de méthane}

La communauté microbienne du rumen est extrêmement diverse, comportant des bactéries, des protozoaires, des champignons (Jouany 1994) et des Archaea. Ces différents microorganismes interagissent pour assurer la dégradation des aliments ingérés par les ruminants, composés principalement de polymères glucidiques.

Le méthane d'origine biologique ${ }^{1}$ est produit par un groupe de microorganismes particuliers, les Archaea méthanogènes. Les Archaea en général ont été longtemps considérés comme des bactéries extrêmophiles ${ }^{2}$. Le travail de Woese et al (1990) a permis de poser les bases de la phylogénie moderne et a montré que les Archaea sont aussi différents des bactéries que celles-ci le sont des eucaryotes; depuis les Archaea constituent à eux seuls le troisième domaine du vivant.

L'énergie nécessaire à la croissance des Archaea méthanogènes est obtenue principalement lors de la production $\mathrm{du}$ $\mathrm{CH}_{4}$. Ils sont capables d'utiliser un nombre restreint de substrats et trois voies métaboliques méthanogènes ont été décrites, en fonction de l'accepteur final d'électrons: hydrogénotrophes (méthanogenèse à partir du $\mathrm{CO}_{2} / \mathrm{H}_{2}$ ), méthylotrophes (méthanogenèse à partir du méthanol et ses dérivés) et acétoclastes (méthanogenèse à partir de l'acétate

\footnotetext{
${ }^{1}$ Par opposition au méthane d'origine géologique produit par exemple lors de l'oxydation du fer.

2 Organisme dont les conditions de vie normales sont mortelles pour la plupart des autres organismes.
} 
et ses dérivés) (Pelmont 2005, Liu et Whitman 2008). Les voies métaboliques complètes avec les enzymes correspondantes ont été récemment récapitulées par Liu et Whitman (2008). Ainsi les Archaea méthanogènes en général peuvent être divisés en trois groupes correspondant à ces trois voies méthanogènes, bien que certaines espèces soient capables d'emprunter deux, voire trois de ces voies.

\section{1 / Les Archaea méthanogènes dans le rumen}

Dans le rumen, les Archaea méthanogènes ne constituent qu'une petite partie de la biomasse microbienne (de 1 à $4 \%$ ) (Lin et al 1997, Yanagita et al 2000) et se caractérisent par une faible diversité aussi bien chez l'ovin que chez le bovin (Whitford et al 2001, Nicholson et al 2007, Wright et al 2007). Les techniques classiques de culture microbienne ont permis d'isoler uniquement 8 espèces d'Archaea méthanogènes du rumen ; l'utilisation d'outils moléculaires a permis d'identifier en revanche un peu moins de mille souches différentes (Kim et al 2011), bien qu'elles n'aient pas de représentants cultivés. Ainsi au niveau moléculaire, les résultats compilés de 14 études (sur des ovins et bovins à différents stades physiologiques, recevant différentes rations) a réparti $93 \%$ des méthanogènes dans trois genres: Méthanobrevibacter (62\% des séquences analysées), Rumen Cluster C (16\%) et Methanomicrobium (15\%) (Janssen et Kirs 2008). Parmi les Methanobrevibacter, genre prédominant, le clade ${ }^{3}$ de M. gottschalkii (M. gottschalkii, $M$. thaueri, M. millerae) est le plus représenté, suivi de près par celui de $M$. ruminantium ( $M$. ruminantium, M. olleyae) (Janssen et Kirs 2008).

Les Archaea méthanogènes dans le rumen sont essentiellement des hydrogénotrophes. Cependant, des séquences appartenant au genre Methanosarcina, caractérisé par le métabolisme versatile de ses membres, ont été identifiées (Denman et al 2007). Les représentants de ce groupe minoritaire utilisent principalement les méthylamines et l'acétate comme substrats et sont des hydrogénotrophes occasionnels (Balch et al 1979, Garcia et al 2000). Ces résultats suggèrent qu'il y aurait dans le rumen il $\mathrm{y}$ aurait un chevauchement de niches méthanogènes avec une possibilité de remplacement de niches. Malgré cela, les Archaea méthanogènes sont incapables d'utiliser la plupart des composés organiques présents dans le rumen, tels les glucides ou les acides gras à chaîne longue. Cette restriction impose une relation nutritionnelle étroite avec les microorganismes non méthanogènes qui utilisent les composés organiques : les protozoaires et les bactéries.

\section{2 / Protozoaires et bactéries dans le rumen}

Les protozoaires ciliés peuvent représenter une proportion importante de la biomasse microbienne du rumen lorsque le $\mathrm{pH}$ est compris entre 6 et 7 . Ils appartiennent à deux grands groupes: les Entodiniomorphes et les Holotriches. Ils se nourrissent de bactéries mais aussi directement de glucides et protéines provenant des aliments ingérés par le ruminant. Les protozoaires jouent un rôle important dans le métabolisme ruminal. Ils sont capables d'《ingérer» des granules d'amidon, des parois végétales, par invagination, et de les «digérer» lentement à l'abri du contenu ruminal. En cas de régime riche en céréales, ils ingèrent rapidement un grand nombre de granules d'amidon et jouent par ce biais un important rôle de compartiment de délai, la fermentation du substrat étant étalée ensuite dans le temps. Sans eux, la vitesse de digestion d'une ration riche en amidon est plus élevée ce qui entraîne une chute du $\mathrm{pH}$ ruminal plus forte et brutale.

Cependant, les protozoaires ne sont pas indispensables au bon fonctionnement du rumen. Ils peuvent être partiellement ou complètement éliminés par un procédé expérimental connu sous le nom de défaunation. Dans certains cas, la défaunation peut avoir des effets bénéfiques sur le métabolisme et la performance animale (Eugène et al 2004). Les ruminants défaunés sont toujours capables de digérer les fibres, grâce à la population bactérienne complexe et diversifiée.

Les bactéries sont les microorganismes les plus nombreux dans le contenu ruminal et leur concentration peut atteindre $10^{11}$ cellules par $\mathrm{mL}$ de jus de rumen. On les classe selon leur principale fonction : les amylolytiques sont celles qui attaquent l'amidon, les cellulolytiques sont celles qui dégradent les fibres (cellulose, hémicelluloses). Si les bactéries cellulolytiques (Fibrobacter succinogenes, Ruminococcus albus, Ruminococcus flavefaciens) n'utilisent que la cellulose et ses produits d'hydrolyse, les fonctions d'autres espèces sont plus larges (figure 1). Ainsi, Butyrivibrio fibrisolvens et Prevotella ruminicola peuvent utiliser de nombreuses sources d'énergie : cellulose, hémicelluloses, amidon, pectines, sucres. Les bactéries agissent par contact: elles adhèrent fortement aux aliments et concentrent l'action de leurs enzymes sur les parois végétales.

Les avancées de la biologie moléculaire ont permis d'aller plus loin dans la caractérisation de ces communautés. Aujourd'hui, il est estimé que seuls 11 et $10 \%$ respectivement des espèces bactériennes (Edwards et al 2004) et des protozoaires (Shin et al 2004) détectés en utilisant les outils moléculaires ont des représentants cultivés. De plus, les études menées jusqu'à présent ont montré qu'aussi bien l'animal hôte (Regensbogenova et al 2004, Welkie et al 2010) que la ration alimentaire (Karnati et al 2003, Sadet et al 2007) influencent la structure (nombres et diversité) de ces deux communautés microbiennes.

\section{3 / Dégradation microbienne des aliments}

Dans le rumen, les microorganismes agissent en synergie pour dégrader les parois végétales de la ration du ruminant. Certaines espèces hydrolysent d'abord les aliments, les produits de cette dégradation sont principalement des sucres, de l'ammoniaque et des minéraux. Ces sucres sont alors fermentés par des microorganismes «fermentaires» pour aboutir à la production d'Acides Gras Volatils (AGV) (figure 1). Au cours de ces processus, les microorganismes tirent l'énergie nécessaire à leur croissance sous forme d'ATP.

Les AGV traversent la paroi du rumen pour couvrir jusqu'à $70 \%$ des besoins énergétiques de l'animal (Hvelplund 1991). Les principaux AGV sont l'acétate, le propionate et le butyrate. Avec une ration de fourrage seul, l'acétate représente en moyenne $70 \%$ des AGV produits, le propionate près de $20 \%$ et le butyrate environ $10 \%$. Avec une ration riche en amidon, la proportion molaire du propionate peut monter jusqu'à $30 \%$; l'addition de glucides solubles (saccharose, lactose) stimule la production de butyrate (jusqu'à 20\%) et à un moindre degré celle du propionate. Dans ces deux cas, la proportion molaire de l'acétate diminue.

Les fermentations ruminales s'accompagnent de la formation de gaz $\left(\mathrm{CO}_{2}, \mathrm{~N}_{2}, \mathrm{H}_{2}, \mathrm{H}_{2} \mathrm{~S}\right)$. Les gaz sont éliminés par la respiration et les éructations régulières, sauf pour la partie qui est dissoute dans le contenu ruminal. En ce qui concerne $\mathrm{l}^{\prime} \mathrm{H}_{2}$ en particulier, l'élévation de sa concentration dans le contenu ruminal empêche l'oxydation

3 Groupe d'organismes issus d'un ancêtre commun. 
Figure 1. Hydrolyse et fermentation microbienne des aliments dans le rumen.

Les réactions qui produisent de l'hydrogène sont en gris ; les réactions hydrogénotrophes sont en rouge. Les fonctions connues des principales espèces bactériennes sont indiquées.

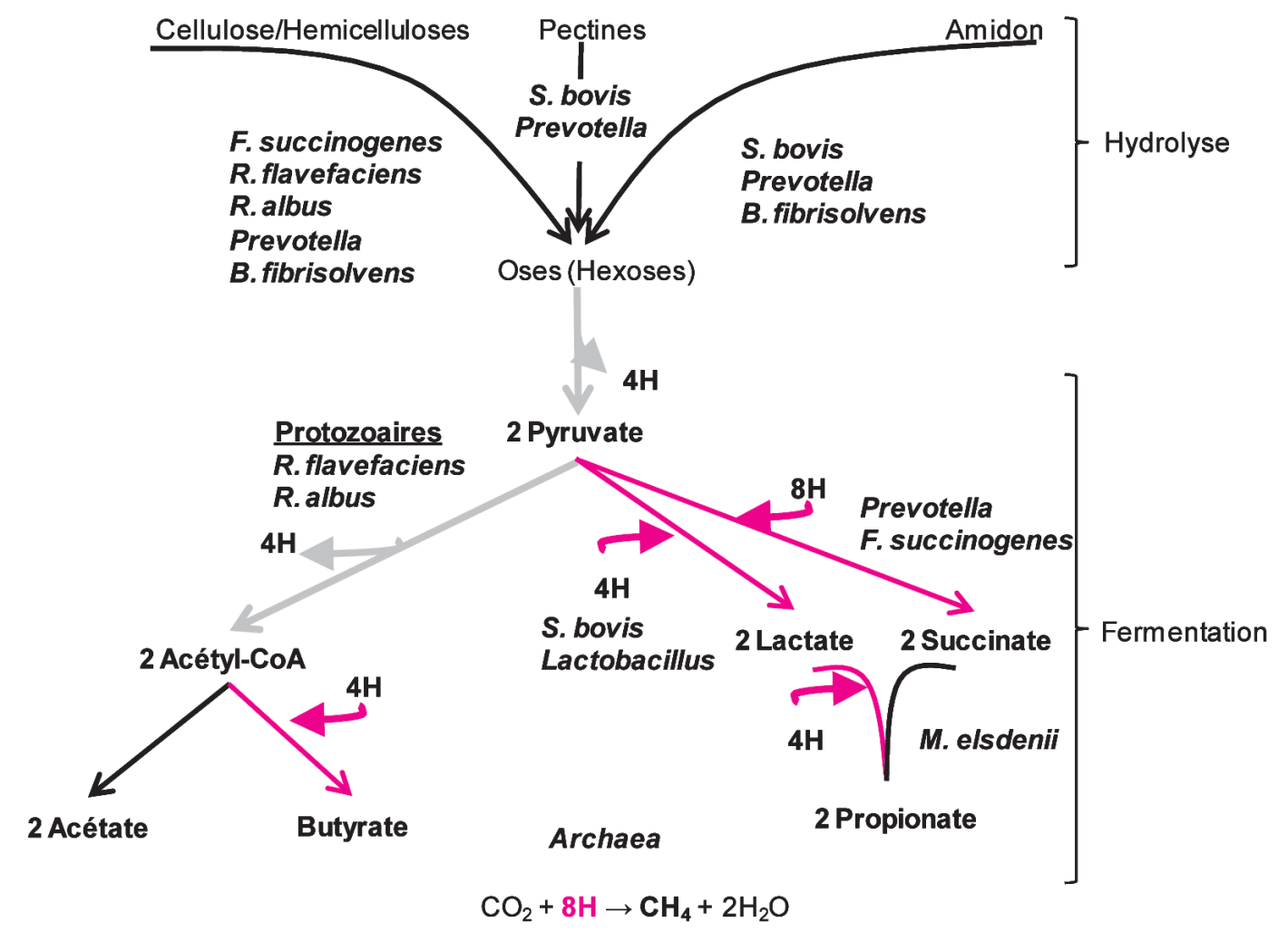

des cofacteurs impliqués dans les voies fermentaires et peut inhiber la dégradation optimale des fibres alimentaires. L'utilisation de $\mathrm{l}^{\prime} \mathrm{H}_{2}$ par les Archaea méthanogènes dans la production de $\mathrm{CH}_{4}$ assure la continuité des fermentations.

Czerkawski (1986) a estimé que 48\% du pool total d' $\mathrm{H}_{2}$ sont utilisés dans la méthanogenèse, $33 \%$ dans la synthèse d'AGV et $12 \%$ dans la biomasse microbienne. Plus récemment, Janssen (2010) a proposé un modèle thermodynamique des fermentations ruminales, régulé par la disponibilité du substrat limitant, notamment $1{ }^{\prime} \mathrm{H}_{2}$. En effet, les voies fermentaires ne sont pas équivalentes en termes de bilan en $\mathrm{H}_{2}$ : les productions d'acétate et de butyrate s'accompagnent de libération d' $\mathrm{H}_{2}$ dans le milieu ruminal alors que la synthèse de propionate est une voie d'utilisation de $1^{\prime} \mathrm{H}_{2}$ (Jouany et Thivend 2008) (figure 1). Paradoxalement, selon le modèle de Janssen (2010), les conditions ruminales qui conduisent à une augmentation des concentrations en $\mathrm{H}_{2}$ dissous dans le contenu ruminal, réduiraient la quantité de $\mathrm{CH}_{4}$ produit par unité de monomère alimentaire dégradé dans le rumen. Quand la concentration d' $\mathrm{H}_{2}$ dissous dans le contenu ruminal est faible, les voies métaboliques menant à la production d' $\mathrm{H}_{2}$ (synthèse de l'acétate en particulier) sont stimulées. Dans ce cas de figure aussi, seuls les microorganismes à grande affinité pour $\mathrm{l}^{\prime} \mathrm{H}_{2}$ peuvent capter le substrat peu disponible. C'est le cas des Archaea méthanogènes et par voie de conséquence une quantité importante de $\mathrm{CH}_{4}$ est produite. En revanche, l'élévation de la concentration en $\mathrm{H}_{2}$ exercerait un effet négatif sur la production d'acétate et stimulerait la production de propionate; $1{ }^{\prime} \mathrm{H}_{2}$ serait ainsi dévié vers la production de propionate aux dépens de la méthanogenèse.

Le rôle central de l' $\mathrm{H}_{2}$ dans le métabolisme ruminal a été souligné dans la plupart des études menées pour explorer les stratégies de réduction des émissions de $\mathrm{CH}_{4}$ par les ruminants. Parmi ces stratégies, la plupart concerne la manipulation de l'écosystème microbien par des additifs et des biotechnologies (défaunation, probiotiques, additifs chimiques, acides organiques...) ou par l'alimentation (modification des éléments constitutifs de la ration, apport d'additifs alimentaires tels que les lipides).

\section{2 / Biotechnologies}

\section{1 / Probiotiques}

Les probiotiques sont définis comme des microorganismes vivants qui, lorsqu'ils sont administrés en quantités appropriées et régulières, ont un effet bénéfique sur l'hôte. L'utilisation de probiotiques dans l'alimentation des ruminants, dans le but ciblé de réduire la méthanogenèse, a fait l'objet de peu d'études jusqu'à maintenant (Chaucheyras et al 2008) et les rares résultats obtenus in vivo ne sont pas convaincants (Doreau et al 2011). McGinn et al (2004) ont rapporté que le produit de levures commerciales Procreatin-7 (Saf Agri) a provoqué une diminution non significative de $3 \%$ de la production du $\mathrm{CH}_{4}$, exprimée en pourcentage de la matière sèche ingérée alors que Levucell SC (Lallemand Inc) n'a eu aucun effet. Chung et al (2011) ont comparé les effets d'une supplémentation avec deux souches de $S$. cerevisiae chez des vaches taries; bien qu'aucun changement significatif dans la production de $\mathrm{CH}_{4}$ n'ait été observé, les souches ont influencé différemment les profils fermentaires. Alors que des études isolées ont montré que $S$. cerevisiae peut stimuler la production de propionate au détriment de l'acétate, cet effet n'est pas retrouvé systématiquement dans la littérature (Newbold et Rode 2006).

A priori, les probiotiques n'auraient pas un effet direct sur les Archaea méthanogènes du rumen. En revanche, $S$. cerevisiae stimule la croissance de certaines bactéries (Wallace et Newbold 
Tableau 1. Caractéristiques thermodynamiques des processus réductifs en anaérobiose.

\begin{tabular}{|c|c|c|}
\hline Processus & $\Delta \mathbf{G}^{{ }^{1}}$ & Affinité pour l'hydrogène $^{2}$ \\
\hline Méthanogenèse & $-139,1$ & 0,67 \\
\hline Acétogenèse & $-111,6$ & 1,26 \\
\hline Sulfato-réduction & $-152,3$ & 0,0013 \\
\hline Dénitrification & $-599,8$ & ND \\
\hline Réduction du fumarate & $-86,2$ & ND \\
\hline
\end{tabular}

1 Valeurs d'enthalpie libre calculées à $\mathrm{pH} 7$, pour une température de $25^{\circ} \mathrm{C}$ et une pression de 1 atmosphère.

2 En milli moles/L, concentrations minimales mesurées pour des cultures pures. ND : information non disponible.

1993). Comme discuté dans le cas de la défaunation (cf. § 2.2), quand la biomasse microbienne augmente, une partie de $l^{\prime} \mathrm{H}_{2}$ issue des fermentations est orientée vers le maintien et la synthèse de nouvelles cellules. Ainsi, il est possible que la stimulation de la synthèse microbienne par $S$. cerevisiae se traduise par la réduction de la méthanogenèse.

Par ailleurs, Chaucheyras-Durand et Durand (2010) ont suggéré que $S$. cerevisiae pourrait stimuler la croissance des bactéries acétogènes capables d'utiliser $l^{\prime} \mathrm{H}_{2}$ dans le rumen, le détournant ainsi de la méthanogenèse. L'acétogenèse réductrice est une voie particulière de biosynthèse de l'acétate par réduction de 2 moles de $\mathrm{CO}_{2}$ par 4 moles $\mathrm{d}^{\prime} \mathrm{H}_{2}$. La flore acétogène est naturellement présente dans le rumen, mais ne peut pas exprimer son potentiel hydrogénotrophe en présence d'Archaea méthanogènes du fait de la moindre affinité pour $1^{\prime} \mathrm{H}_{2}$ (tableau 1). En absence de méthanogènes, l'acétogenèse réductrice est la principale voie hydrogénotrophe (Fonty et al 2007) et peut être stimulée par des probiotiques. Chaucheyras et al (1995) ont montré que la consommation d' $\mathrm{H}_{2}$ par une bactérie acétogène en co-culture avec une souche méthanogène était stimulée en présence de $S$. cerevisiae, sans pourtant avoir des effets sur la consommation $\mathrm{d}^{\prime} \mathrm{H}_{2}$ de la souche méthanogène ou sur la production de $\mathrm{CH}_{4}$. Pour obtenir des réductions satisfaisantes de la méthanogenèse dans le rumen, il faudrait parallèlement inhiber les méthanogènes et stimuler les acétogènes. Malgré les recherches réalisées jusqu'à présent, la faisabilité de cette stratégie est encore à démontrer. Les pistes à étudier sont la mise au point de probiotiques qui i) limitent la production $\mathrm{d}^{\prime} \mathrm{H}_{2}$ dans le rumen en favorisant le développement des bactéries cellulolytiques non productrices d' $\mathrm{H}_{2}$ telles que $F$. succinogenes ou en inhibant les protozoaires, ii) favorisent l'utilisation de 1 ' $\mathrm{H}_{2}$ en orientant les fermentations du rumen vers le propionate (les bactéries productrices de propionate) et/ou l'acétate (voie de l'acétogenèse réductrice).

La piste des additifs microbiens mérite d'être approfondie. L'avenir des probiotiques pour réduire la méthanogenèse est lié à une meilleure connaissance de leurs modes d'action et à la mise au point de souches microbiennes plus efficaces, ce qui est envisageable grâce aux progrès des biotechnologies.

\section{2 / Défaunation}

Les principaux AGV produits par les protozoaires du rumen sont le butyrate et l'acétate, donc des voies métaboliques productrices d' $\mathrm{H}_{2}$. Il n'est donc pas étonnant que les Archaea méthanogènes aient été retrouvés attachés à la surface des protozoaires (ectosymbiose) ou encore à l'intérieur des cellules (endosymbiose). Les Archaea méthanogènes associés aux protozoaires seraient responsables de 9 à $25 \%$ du $\mathrm{CH}_{4}$ produit dans le rumen (Newbold et al 1995). D'un autre côté, une baisse moyenne de $10 \%$ des émissions de $\mathrm{CH}_{4}$ est observée après défaunation, cette valeur pouvant varier en fonction du régime alimentaire du ruminant (Morgavi et al 2010). La réduction des émissions de $\mathrm{CH}_{4}$ suite à la défaunation peut être expliquée par un certain nombre de facteurs (Doreau et al 2011); dans cet article nous nous limiterons aux mécanismes microbiens.

La présence des protozoaires assure la stabilité du $\mathrm{pH}$ ruminal (Eugène et al
2004) en régulant les fermentations ruminales comme mentionné précédemment. Les réductions les plus significatives de la méthanogenèse après l'élimination des protozoaires ont été observées avec des rations riches en amidon (Morgavi et al 2010) et peuvent donc être partiellement attribuées à la corrélation positive entre la production de $\mathrm{CH}_{4}$ et le $\mathrm{pH}$ ruminal (Lana et al 1998). En effet, le pH optimal pour la croissance des Archaea méthanogènes fluctue entre 6,1 et 7,8 en fonction des espèces (Miller et Wolin 1985, Jarvis et al 2000, Millet et Lin 2002). Des cultures mixtes de microorganismes du rumen incubées à $\mathrm{pH} 7$ ont produit la même quantité de $\mathrm{CH}_{4}$ que celles incubées à $\mathrm{pH} 6$; alors qu'à $\mathrm{pH} 6$ et avec $80 \mathrm{mM}$ d'acétate dans le milieu, la méthanogenèse a été complètement inhibée (Van Kessel et Russell 1996). L'acétate est hautement lipophile et peut traverser les membranes microbiennes pour s'accumuler à l'intérieur des cellules en créant un gradient de $\mathrm{pH}$. Ceci se traduit par une inhibition de l'activité métabolique des Archaea méthanogènes qui peut être levée, soit en augmentant le $\mathrm{pH}$, soit en diminuant la concentration en acétate dans le milieu externe (Van Kessel et Russell 1996).

On pourrait donc s'attendre à des changements brusques dans la structure (nombre et diversité) de la communauté méthanogène et l'orientation des fermentations ruminales quand les protozoaires sont éliminés (tableau 2). Dans l'étude de Takenaka et Itabashi (1995), utilisant des techniques classiques de culture microbienne, le nombre des méthanogènes viables avait été divisé par 10 après la défaunation. Cependant, la production de $\mathrm{CH}_{4}$ par les animaux n'a pas été mesurée dans cette étude. Les résultats de comptage ne sont pas confirmés par les quantifications moléculaires ciblant des gènes particuliers. Le nombre des gènes $r r s^{4}$ des Archaea par mL de contenu ruminal a doublé après la défaunation chez des moutons (Machmüller et al 2003) suggérant une communauté méthanogène plus nombreuse, sans changement pourtant dans la quantité de $\mathrm{CH}_{4}$ produit. Les résultats de la quantification du gène rrs sont cohérents avec l'augmentation du nombre des copies du gène $m c r A^{5}$ observée chez des ovins défaunés depuis 3 mois (Popova et al 2010) ou 2 ans (Mosoni et al 2011), dont la production de $\mathrm{CH}_{4}$ avait diminué respectivement d'environ 10 et $20 \%$.

\footnotetext{
4 Gène codant pour l'ARN ribosomal $16 \mathrm{~S}$; ce gène est la base de la phylogénie moderne et permet d'identifier les microorganismes détectés.

5 Gène codant pour la protéine methyl co-enzyme M réductase impliqué dans la dernière réaction de la voie métabolique de la méthanogenèse. Du fait de son importance dans la survie de la cellule méthanogène, ce gène a été bien conservé au cours de l'évolution et peut être utilisé pour détecter et identifier les Archaea méthanogènes.
} 
Tableau 2. Effets de la défaunation sur la population méthanogène et les paramètres fermentaires.

\begin{tabular}{|c|c|c|c|c|l|}
\hline $\begin{array}{c}\text { Archaea } \\
\text { méthanogènes } \\
\text { (nombres) }(\%)\end{array}$ & $\mathrm{CH}_{4}$ & $\begin{array}{c}\text { AGV } \\
\mu \mathrm{mol} / \mathrm{mL}\end{array}$ & $\begin{array}{c}\text { Butyrate } \\
\text { mol/mol AGV }\end{array}$ & $\begin{array}{c}\text { Acétatel } \\
\text { Propionate }\end{array}$ & \multicolumn{1}{|c|}{ Références } \\
\hline+10 & $\begin{array}{c}-20 \% \\
\left(\mathrm{CH}_{4} \mathrm{~L} / \mathrm{kg} \mathrm{MSI}\right)\end{array}$ & $\begin{array}{c}\text { Pas de } \\
\text { changement }\end{array}$ & $-33 \%$ & $-26 \%$ & $\begin{array}{l}\text { Mosoni et al } \\
2011\end{array}$ \\
\hline+3 & $\begin{array}{c}-11 \% \\
\left(\mathrm{CH}_{4} \mathrm{~L} / \mathrm{kg} \mathrm{MSI}\right)\end{array}$ & $+14 \%$ & $-16 \%$ & $-12 \%$ & $\begin{array}{l}\text { Popova et al } \\
2010\end{array}$ \\
\hline-998 & $\mathrm{ND}$ & $\boldsymbol{\pi}^{a}$ & $\mathbf{y}^{\mathrm{a}}$ & $\mathbf{y}^{\mathrm{a}}$ & $\begin{array}{l}\text { Takenaka et al } \\
1995\end{array}$ \\
\hline+53 & $\begin{array}{c}\text { Pas de } \\
\text { changement }\end{array}$ & $\begin{array}{c}\text { Pas de } \\
\text { changement }\end{array}$ & $\begin{array}{c}\text { Pas de } \\
\text { changement }\end{array}$ & $-25 \%$ & $\begin{array}{l}\text { Machmüller } \text { et al } \\
2003\end{array}$ \\
\hline
\end{tabular}

ND : information non disponible dans la publication.

a Valeur non disponible dans la publication.

Dans l'étude de Mosoni et al (2011), les outils d'empreinte moléculaire ${ }^{6}$ n'ont révélé aucune différence significative entre les communautés méthanogènes des animaux faunés et défaunés. Dans notre essai, nous avons constaté un changement dans l'abondance des membres des ordres des Methanobacteriales ou des Methanomicrobiales en présence ou absence de protozoaires. Les Methanobacteriales étaient plus abondants chez les animaux défaunés (65\% des séquences retrouvées contre $35 \%$ chez les animaux faunés), alors que la tendance était inversée en ce qui concerne les Methanomicrobiales (10\% des clones chez les animaux défaunés contre $25 \%$ chez les animaux faunés) (Popova 2011). A l'inverse, les membres de la famille des Methanobacteriaceae (ordre Methanobacteriales) constituaient 99\% des Archaea méthanogènes retrouvés associés aux protozoaires (Sharp et al 1998) ; leur nombre a diminué au profit des membres de l'ordre des Methanomicrobiales (essentiellement retrouvés libres dans le contenu ruminal), après l'élimination des protozoaires. Selon la revue de Janssen et Kirs (2008), les genres d'Archaea méthanogènes associés aux protozoaires sont les mêmes que ceux majoritairement retrouvés, Methanobrevibacter, Methanomicrobium ou encore le clade Rumen Cluster C (RCC). De plus, il n'est pas encore bien établi si toutes les espèces de protozoaires maintiennent des relations symbiotiques avec les Archaea méthanogènes. La diminution de la production de $\mathrm{CH}_{4}$ par les animaux défaunés, pourrait être expliquée par un changement dans la diversité des Archaea vers des espèces (ou souches) moins efficaces dans la production de $\mathrm{CH}_{4}$.

D’un autre côté, il a été montré que le nombre des méthanogènes associés aux protozoaires augmente juste après la prise alimentaire et diminue rapidement après (Tokura et al 1997). Stumm et al (1982) ont montré que quand la contribution relative des protozoaires à la production totale d' $\mathrm{H}_{2}$ dans le rumen diminue, le nombre d'association ectosymbiotiques avec les Archaea méthanogènes diminue également. De plus, des effets inhibiteurs de la moindre disponibilité en $\mathrm{H}_{2}$ sur l'activité méthanogène dans le rumen de moutons défaunés ont été démontrés en mesurant l'expression du gène fonctionnel $\mathrm{mcr} A$ (Popova 2011). En absence de protozoaires, la production de méthane avait diminué et la population méthanogène était 2,5 fois moins active qu'en présence de protozoaires. Cette baisse dans l'activité des Archaea méthanogènes est probablement liée à une moindre disponibilité de l' $_{2}$.

L'élimination des protozoaires est souvent associée à une augmentation de la proportion molaire du propionate aux dépens de celles de l'acétate et surtout du butyrate (Eugène et al 2004). Comme discuté précédemment, ces réorientations fermentaires (tableau 2) sont à l'origine d'une moindre disponibilité de l' $\mathrm{H}_{2}$ pour la méthanogenèse. Elles peuvent être attribuées au métabolisme des protozoaires (producteurs importants de butyrate), mais également à leur activité prédatrice envers les bactéries. En effet, en absence de protozoaires, le nombre des bactéries est plus élevé (Ozutsumi et al 2005, 2006 ; Mosoni et al 2011); la croissance et le maintien de la biomasse bactérienne exige également une réorientation de $1^{\prime} \mathrm{H}_{2}$ vers la synthèse de nouvelle cellules, mais aussi de protéines bactériennes. Certaines études ont suggéré une activité prédatrice sélective envers les $R$. albus et $R$. flavefaciens (Ozutsumi et al 2006) dont le nombre augmente avec l'élimination des protozoaires, bien qu'il puisse également s'agir, comme suggéré par Mosoni et al (2011), d'une compétition pour le substrat entre protozoaires et bactéries fibrolytiques.

Les réductions observées dans les émissions de $\mathrm{CH}_{4}$ chez les animaux défaunés ne peuvent pas a priori être expliquées par une communauté méthanogène moins abondante. Des changements dans la diversité ont été observés, mais l'implication des différentes espèces d'Archaea méthanogènes (en présence ou absence de protozoaires) doit encore être démontrée. La diminution de la quantité d' $\mathrm{H}_{2}$ disponible pour la méthanogenèse est le point commun entre les différentes études.

Des techniques de défaunation applicables dans la pratique sont nécessaires. Une défaunation plus ou moins importante peut être obtenue en utilisant certains additifs extraits de plantes (cf. §3.2).

\section{3 / Vaccins et anticorps}

La vaccination des animaux contre les Archaea méthanogènes permettrait de diminuer la production de $\mathrm{CH}_{4}$ sans altérer la digestion, la performance animale ou la qualité des produits (Wright et al 2004b). Il s'agit d'une stimulation du système immunitaire de l'animal afin de produire des anticorps antiméthanogènes qui via la salive rejoindront le rumen où ils inhiberont les Archaea. Parmi les trois vaccins formulés à ce jour (Wright et al 2004b, Williams et al 2009), un seul a réussi à baisser les émissions de $\mathrm{CH}_{4}$ de $8 \%$ (Wright et al 2004b). Dans cette dernière étude, il a été déterminé a posteriori que les animaux traités avaient reçu un vaccin ne ciblant que $20 \%$ des espèces d'Archaea méthanogènes présents dans le rumen; donc en ciblant une plus grande proportion de la population, la diminution des émissions de $\mathrm{CH}_{4}$

\footnotetext{
${ }^{6}$ Méthodes indépendantes de la culture utilisées dans l'étude des communautés microbiennes ; permettent d'obtenir une image assez exhaustive des communautés via l'utilisation de marqueurs (rss le plus souvent).
} 
devrait être plus importante. Ceci implique que la composition du vaccin soit prédéterminée par la composition (espèces, souches) précise de la communauté méthanogène des animaux à traiter. Bien que les outils moléculaires actuels permettent une identification rapide des microorganismes, la diversité des populations, et en particulier celle des méthanogènes, est sujette à des fluctuations liées entre autres au régime alimentaire (Williams et al 2009) et à l'animal hôte (Jeyanathan et al 2011). Ceci rend difficile la formulation d'un vaccin. En effet, les Archaea méthanogènes dominants ciblés par le vaccin peuvent être rapidement remplacés par des nouveaux représentants de ce groupe de microorganismes (Williams et al 2009).

Dans le même contexte, des anticorps spécifiques de trois souches méthanogènes du rumen ont été isolés à partir d'œufs de poules immunisées contre Methanobrevibacter smithii PS, Methanobrevibacter ruminantium et Methanosphaera stadmanae (Cook et al 2008). L'administration des anticorps n'a baissé la production de $\mathrm{CH}_{4}$ des contenus ruminaux incubés in vitro que de manière transitoire. Tout comme dans le cas de la vaccination «directe», les auteurs ont émis l'hypothèse que la production de $\mathrm{CH}_{4}$ est rapidement revenue au niveau initial à cause des Archaea méthanogènes encore non isolés et donc non ciblés par les anticorps.

L'adaptation de la population méthanogène est un point important à prendre en compte afin de prévoir l'efficacité d'un vaccin ou d'un anticorps à long terme. Egalement, la formulation de molécules «universelles» nécessite encore des recherches. Une autre difficulté de cette stratégie est la production d'une réponse immunitaire adéquate, ainsi que le mode d'administration des vaccins ou des anticorps dans le rumen en conditions d'élevage.

\section{3 / Additifs}

\section{1 / Additifs chimiques}

\section{a) Les nitrates}

Des additifs chimiques, notamment le nitrate et le sulfate, ont été expérimentés comme accepteurs d'électrons à la place du $\mathrm{CO}_{2}$ (Weimer et al 1999).

D'un point de vue thermodynamique, les réductions successives du nitrate en nitrite puis en ammoniaque fournissent plus d'énergie que la réduction du $\mathrm{CO}_{2}$ en $\mathrm{CH}_{4}$ (tableau 1). Ces processus pourraient être une voie intéressante d'élimination $\mathrm{d}^{\prime} \mathrm{H}_{2}$ si le nitrate est disponible en quantité suffisante dans le rumen. La réduction du nitrate en ammoniaque consomme 8 électrons et ainsi chaque mole de nitrate réduit pourrait diminuer la production de $\mathrm{CH}_{4}$ d'une mole. L'ammoniaque généré sera disponible pour l'anabolisme et serait un apport important d'azote avec des régimes alimentaires pauvres en protéines qui peuvent limiter la synthèse des protéines microbiennes.

Un grand nombre d'espèces bactériennes dans le rumen a la capacité de réduire le nitrate et/ou le nitrite en ammoniaque. Le nitrate ajouté à l'alimentation des moutons favorise rapidement la multiplication des microbes qui utilisent ce substrat comme source d'azote, ou ce qui semble être plus probable, induit ou augmente l'activité nitrate-réductase chez les microbes qui sont déjà présents dans le rumen. En effet, aucun changement dans le nombre des bactéries ou des protozoaires, n'a été observé après la supplémentation de la ration avec des nitrates chez des ovins (Nolan et al 2010, Zijderveld et al 2011). La concentration en AGV dans le contenu ruminal n'a pas été influencée (Zijderveld et al 2010) ou a augmenté (Nolan et al 2010) suite à l'apport de nitrates ; cette méthodologie n'aurait donc pas d'effets négatifs sur les processus fermentaires dans le rumen. En revanche, la moindre disponibilité de 1 ' $\mathrm{H}_{2}$ ou encore peut-être un effet toxique direct du nitrate (nitrite), a divisé par 10 le nombre des Archaea méthanogènes, permettant ainsi d'expliquer la baisse observée dans les émissions de $\mathrm{CH}_{4}$ chez les ovins (Zijderveld et al 2010).

Toutefois, la supplémentation de la ration avec des nitrates peut se révéler toxique pour l'animal. Les nitrates contenus dans certaines plantes ne constituent pas en soi un problème pour les microorganismes du rumen qui possèdent les enzymes nécessaires pour décomposer le nitrate en ammoniaque. Cependant de fortes charges en nitrates alimentaires peuvent submerger la capacité des microorganismes du rumen à dégrader complètement le nitrate en ammoniaque et le niveau du nitrite, un composé intermédiaire, peut augmenter. Le nitrite est le vrai problème car il est toxique pour les bactéries cellulolytiques. Cela peut aboutir à la digestibilité réduite des fibres dans le rumen, qui à son tour, se traduira par une prise alimentaire réduite. De plus, si les nitrites s'accumulent dans le rumen, ils peuvent passer à travers la paroi du rumen dans le sang. Là, ils se lient à l'hémoglobine en créant la méthémoglobine. La méthémoglobine a une capacité plus faible de transporter l'oxygène que l'hémoglobine ${ }^{7}$, ce qui réduit l'apport d'oxygène à tous les tissus (Sar et al 2004). L'apport de $\beta$ 1-4 galacto-oligosides, de nisine (Sar et al 2004) ou encore de sulfates (Zijderveld et al 2010) en plus de la supplémentation en nitrates ont permis de maintenir la méthémoglobine sous le seuil de détection. En effet, les microorganismes sulfato-réducteurs sont naturellement présents dans l'écosystème microbien ruminal, mais moins abondants que les Archaea méthanogènes (Morvan et al 1994).

Les nitrates sont donc une piste intéressante à explorer pour réduire les émissions de $\mathrm{CH}_{4}$. Des études supplémentaires sont nécessaires pour mieux comprendre si les réductions observées dans la méthanogenèse sont dues à une action directe (toxique) sur les Archaea méthanogènes. Il est également possible que ce soit le résultat d'un effet indirect, comme la réorientation de $\mathrm{l}^{\prime} \mathrm{H}_{2}$ vers d'autres voies métaboliques via la stimulation de communautés microbiennes particulières.

\section{b) Les composés anti-méthanogènes}

L'utilisation de composés antiméthanogènes (bromocholorométhane (BCM), bromoéthanesulfonate (BES), chloroforme) a des effets drastiques sur les Archaea du rumen, en perturbant spécifiquement la méthanogenèse (Ungerfeld et al 2004). Le BCM est un analogue halogéné du méthane qui réagit avec la vitamine $B_{12}$ et inhibe ainsi une étape cobalamine-dépendante de la voie métabolique de la méthanogenèse. Le BES est un analogue de structure du 2-mercaptoéthanesulfonate (coenzyme M, CoM) et interfère dans la méthanogenèse en inhibant la déméthylation réductive de $\mathrm{CH}_{3}-\mathrm{S}-\mathrm{CoM}$. Le chloroforme est connu pour inhiber l'action des enzymes cobalaminedépendantes, telles que la méthyl-CoM réductase qui catalyse l'étape ultime de la méthanogenèse.

L'ajout de BCM in vitro fait passer la quantité de $\mathrm{CH}_{4}$ produit, de $30 \%$ des gaz totaux à des traces, en éliminant complètement la population méthanogène (Goel et al 2009). Le BES réduit in vitro la quantité de $\mathrm{CH}_{4}$ produit de $86 \%$ en réduisant de presque 10 fois le

\footnotetext{
${ }^{7}$ La méthémoglobine contient un ion ferrique $\left(\mathrm{Fe}^{3+}\right)$ à la différence de l'hémoglobine qui renferme un ion ferreux $\left(\mathrm{Fe}^{2+}\right) ; l^{\text {'ion }} \mathrm{Fe}^{3+}$ forme une liaison irréversible avec l'oxygène qui ne peut, de ce fait, être distribué aux tissus.
} 
nombre des méthanogènes (Guo et al 2007). Les émissions de $\mathrm{CH}_{4}$ de vaches taries ont été réduites de $94 \%$ après l'administration de chloroforme dans la ration (Knight et al 2011). L'efficacité de cette méthode sur la production de $\mathrm{CH}_{4}$ à long terme reste à étudier, tout comme les effets secondaires sur les performances et le bien-être animal d'une supplémentation de la ration avec du chloroforme.

Le taux de recouvrement de l' $\mathrm{H}_{2}\left[\left(\mathrm{H}_{2}\right.\right.$ utilisé/ $\mathrm{H}_{2}$ produit) x 100] diminue d'environ $60 \%$ dans l'étude de Goel et al (2009) et de 40\% dans l'étude de Guo et al (2007). Le calcul tient compte de l'incorporation de $\mathrm{l}^{\prime} \mathrm{H}_{2}$ dans les $\mathrm{AGV}$ et le $\mathrm{CH}_{4}$, mais pas de la partie utilisée dans la synthèse de la biomasse microbienne qui était améliorée avec l'ajout de BCM (Goel et al 2009). Bien que ces inhibiteurs soient considérés comme spécifiques aux Archaea méthanogènes, in vitro en revanche ces molécules stimulent le développement de la population bactérienne. La croissance de Fibrobacter succinogenes a été stimulée aussi bien par le BCM $(+68 \%$, Goel et al 2009) que par le BES (+50\%, Guo et al 2007). F. succinogenes est le plus important producteur de succinate dans des régimes à base de foin (Moss et al 2000) ; le succinate est ensuite métabolisé en propionate par d'autres espèces bactériennes dans le rumen. La prolifération de $F$. succinogenes peut s'expliquer par la disparition des Archaea méthanogènes, concurrents pour $1^{\prime} \mathrm{H}_{2}$ qui devient toute de suite plus disponible pour la synthèse de succinate et de propionate.

In vivo, l'ajout de BCM diminue la production de $\mathrm{CH}_{4}$ de $59 \%$, et le nombre des Archaea méthanogènes de 34\% (Denman et al 2007). La concentration des AGV n'a pas été affectée par le traitement, ce qui suggère que même si on peut s'attendre à une accumulation d' $\mathrm{H}_{2}$ dans le milieu ruminal, celle-ci n'a pas inhibé les fermentations ruminales. D'un autre côté, le nombre des Archaea méthanogènes n'avait diminué significativement que 8 heures après la première administration journalière de l'inhibiteur et avait retrouvé sa valeur initiale 4 heures plus tard, alors que la baisse dans la méthanogenèse s'était maintenue tout au long de la journée. Il est possible que l'additif ait eu plutôt des effets bactériostatiques que bactéricides ou qu'il ait sélectionné des espèces moins efficaces dans la production de $\mathrm{CH}_{4}$. Les membres de l'ordre des Methanobacteriales étaient dominants (74\%) dans la banque de clones construite avant l'administration de BCM et leur abondance n'était que $56 \%$ après l'administration de BCM. Les auteurs en concluent que les méthanogènes dominants ont été plus sensibles au BCM et que d'autres ordres, moins sensibles, ont repris le dessus une fois la niche appauvrie (Denman et al 2007). Le BCM inhibe une étape de la méthanogenèse qui exige la cobalamine (vitamine B12); il est possible que des voies non-cobalamine-dépendantes existent dans le rumen ce qui mènerait probablement à la sélection de groupes particuliers de méthanogènes si la pression sélective exercée par le BCM est maintenue à long terme.

De même, l'inclusion de chloroforme dans la ration alimentaire réduit rapidement le nombre et la diversité (nombre d'espèces différentes présentes) des Archaea méthanogènes dans le rumen de vaches (Knight et al 2011). Moins d'un mois après le début du traitement cependant, les auteurs ont constaté une augmentation de $258 \%$ dans le nombre des Archaea méthanogènes viables. Etonnamment, le clade RCC n'a pas été affecté par la présence de chloroforme et les membres de ce groupe phylogénétique sont même devenus prédominants à la fin de l'expérimentation. Concernant les membres du clade Methanobrevibacter dont le nombre a brusquement décliné suite au traitement, leur abondance est revenue à l'état initial un mois après, bien que la diversité ait été réduite (moins d'espèces (souches) différentes détectées).

Les réductions observées de la méthanogenèse lors de l'utilisation d'additifs anti-méthanogènes seraient reliées à une communauté méthanogène moins abondante. Cependant, des changements dans la diversité de cette communauté sont également observés dans certaines études ; on peut donc s'attendre à ce que l'utilisation de cette stratégie à long terme donne lieu à des adaptations microbiennes.

\section{2 / Acides organiques}

Les acides organiques tels le fumarate et le malate sont des intermédiaires importants dans la production de propionate : le malate est déshydraté en fumarate qui est réduit en succinate en utilisant $1^{\prime} \mathrm{H}_{2}$; le succinate est décarboxylé en propionate. In vitro, l'utilisation des acides organiques diminue la méthanogenèse en stimulant la production d'AGV, en particulier du propionate menant à baisser le ratio molaire acétate : propionate (Doreau et al 2011).

Parmi les bactéries capables d'utiliser le fumarate, on trouve des fibrolytiques (F. succinogenes), mais aussi des amylolytiques (Prevotella spp, Selenomonas ruminantium $\mathrm{spp})$. Ainsi, la réduction $\mathrm{du}$ fumarate pourrait jouer un rôle important dans le maintien d'une faible concentration en $\mathrm{H}_{2}$ dans le rumen. Cependant, la réduction du fumarate est thermodynamiquement moins favorable (tableau 1) que la méthanogenèse, ce qui expliquerait la faible capacité de ces bactéries à entrer en compétition avec les Archaea méthanogènes.

L'utilisation du fumarate paraît prometteuse en théorie, étant donné que la conversion d'une mole de fumarate en propionate consommerait une mole d'équivalent réducteur $\left(\mathrm{H}_{2}\right)$, et diminuerait la production de $\mathrm{CH}_{4}$ de 0,25 mole ( 4 moles d' $\mathrm{H}_{2}$ sont utilisées pour réduire le $\mathrm{CO}_{2}$ en $\mathrm{CH}_{4}$ ). En pratique, selon la méta-analyse d'Ungerfeld et al (2007), la production de $\mathrm{CH}_{4}$ in vitro ne diminue que de $0,037 \mu$ mol par $\mu$ mol de fumarate ajouté. En effet, une partie du fumarate est utilisée pour produire de l'acétate en libérant 2 moles d' $\mathrm{H}_{2}$, ce qui contrebalance leur incorporation dans la production de propionate. Les résultats in vivo sont encore moins concluants. Les émissions de $\mathrm{CH}_{4}$ ont diminué, n'ont pas changé ou ont augmenté avec l'ajout de fumarate (Ungerfeld et al 2007). Le calcul fait par Newbold et al (2005) a montré que théoriquement pour réduire de $10 \%$ les émissions journalières de $\mathrm{CH}_{4}$ d'une vache laitière (estimées à $500 \mathrm{~L} / \mathrm{j}$ ), l'animal devrait ingérer $1,4 \mathrm{~kg} /$ jour de fumarate di-sodique, ce qui est difficilement praticable. Au-delà de la stœchiométrie, si le fumarate n'est pas considéré comme un simple substrat et exerce un effet négatif sur certains microorganismes, on peut imaginer une réponse différente. Mais actuellement, à notre connaissance, il n'y a pas d'étude publiée sur les effets de la supplémentation des rations avec du fumarate sur l'écosystème microbien in vivo et en particulier sur les Archaea méthanogènes. Il serait intéressant $i$ ) de voir si les bactéries réductrices de fumarate réussissent à long terme à prendre le dessus sur les Archaea méthanogènes dans le cadre d'un apport de fumarate seul ; ii) de contrôler s'il n'y a pas un changement dans la population méthanogène essentiellement hydrogénotrophe dans les conditions normales, vers une population préférentiellement utilisatrice de formate.

L'utilisation des acides organiques, intermédiaires importants dans les voies métaboliques ruminales, pourrait favoriser la production de propionate. L'efficacité de cette stratégie in vivo et sur le long terme reste à démontrer.

\section{3 / Extraits de plantes et huiles essentielles}

Ces dernières années, l'exploration de phyto-molécules bioactives en tant qu'additifs alimentaires naturels a reçu 
une grande attention de la part des nutritionnistes et des microbiologistes du rumen pour modifier favorablement les fermentations (Jouany et Morgavi 2007, Patra et Saxena 2009). Un grand nombre de molécules végétales, telles que les saponines, les tannins, de même que les huiles essentielles ont sollicité l'intérêt des chercheurs par leur capacité à inhiber la méthanogenèse, améliorer le métabolisme des protéines et la productivité animale ou encore augmenter le contenu d'acide linoléique conjugué dans des produits alimentaires d'origine animale.

\section{a) Les saponines}

Les saponines sont des détergents naturels qui possèdent des propriétés membranolytiques. Elles forment des complexes avec les stérols des membranes cellulaires essentiellement des eucaryotes (protozoaires et champignons dans le rumen) et provoquent la lyse cellulaire. La réduction des émissions de $\mathrm{CH}_{4}$ observée quand les animaux reçoivent des rations riches en saponines (revues de Beauchemin et al 2009, Martin et al 2010) peuvent partiellement être attribuées à la toxicité de ces molécules envers les protozoaires du rumen. Newbold et al (1997) ont trouvé qu'une saponine présente dans Sesbania sesban (arbre africain) est fortement toxique pour les protozoaires dont le nombre a diminué de $60 \%$ en 4 jours dans le rumen de moutons. Après 10 jours, cependant, la population de protozoaires dans le rumen était revenue à son niveau initial. La sensibilité des protozoaires à $S$. sesban n'ayant pas changé entre temps, les auteurs ont conclu à une adaptation de la population bactérienne qui conduit à une dégradation des saponines (Newbold et al 1997).
Yucca schidigera (une autre plante riche en saponines), broyée et administrée via la canule à faibles (20 g/jour) ou fortes (60 g/jour) doses, a diminué la population de protozoaires de $42 \%$ chez des génisses (Hristov et al 1999) sans effet dose. Après 14 jours de traitement, le nombre des protozoaires restait faible suggérant l'absence d'adaptation de la part des protozoaires et des bactéries du rumen. En revanche, Benchaar et al (2008) ont supplémenté la ration de vaches laitières avec $6 \mathrm{~g} / \mathrm{j}$ de saponines de $Y$. schidigera, sans observer d'effets négatifs sur les protozoaires. Hormis ces quelques divergences, qui pourraient s'expliquer par des quantités administrées ou méthodes d'administration différentes, l'activité anti-protozoaire des saponines est l'effet le plus fréquemment rapporté dans les études (Patra et Saxena 2009). Toutefois, bien que les réductions des émissions de $\mathrm{CH}_{4}$ avec des rations contenant $\mathrm{S}$. saponaria chez des animaux faunés soient plus prononcées que chez les animaux défaunés (-29\% vs - 14\%; Hess et al 2003), la baisse dans la méthanogenèse ne serait pas uniquement associée à leur toxicité envers les protozoaires. Enfin, on ne sait pas si la sensibilité de toutes les espèces de protozoaires est identique ou si la ration ne joue pas un rôle dans la sélection des bactéries capables de métaboliser ces toxines.

L'activité inhibitrice des saponines sur les Archaea (étudiée essentiellement in vitro) varie en fonction de la nature de la molécule (tableau 3). Les effets de $S$. sesban sur la méthanogenèse étaient plus prononcés avec une ration riche en concentré qu'avec une ration à base de fourrage (Goel et al 2008). Les saponines des fruits de $S$. rarak ajoutées à hauteur de $4 \mathrm{mg} / \mathrm{mL}$ ont réduit in vitro le nombre des ARNr 16S des Archaea; les concentrations plus basses n'ont pas eu d'effets significatifs (Wina et al 2005) (tableau 3). La paroi cellulaire des Archaea diffère de celle des autres procaryotes, mais aussi de celle des eucaryotes par sa composition en lipides et protéines unique dans le monde vivant. Il est possible que cette particularité leur confère une résistance à certaines saponines. L'ajout de la saponine du thé dans des cultures pures de Methanobrevibacter ruminantium n'a pas eu d'effet ni sur la production de $\mathrm{CH}_{4}$, ni sur le nombre des cellules ou sur leur activité métabolique mesurée via l'expression du gène fonctionnel mcrA (Guo et al 2008). A l'inverse, la saponine de thé a baissé la production de $\mathrm{CH}_{4}$ de $8 \%$ dans des cultures mixtes du rumen sans affecter le nombre des méthanogènes, mais en diminuant leur activité métabolique de $76 \%$ (Guo et al 2008). Les saponines contenues dans Sesbania ont diminué la population méthanogène de $78 \%$ sans que ceci n'ait d'effet sur la production de $\mathrm{CH}_{4}$ in vitro (Goel et al 2008). Ces résultats divergents peuvent être dus à une efficacité différente des espèces méthanogènes dans la production de $\mathrm{CH}_{4}$. A notre connaissance, des études de diversité des méthanogènes n'ont pas été réalisées avec des rations riches en saponines. Il serait intéressant de voir si des espèces particulières ne sont pas sélectionnées parce qu'elles sont résistantes aux saponines.

\section{b) Les tannins}

Les tannins sont des composés hydrosolubles polyphénoliques qui peuvent précipiter les protéines. Les études relatives aux effets sur les protozoaires sont contradictoires. Dans certaines études le nombre des ciliés ne change pas (Newbold et al 1997), alors que dans

Tableau 3. Effets des extraits de plantes sur la concentration des Archaea méthanogènes du rumen.

Les différents modes d'expression de la concentration microbienne sont indiqués en italique au-dessus des valeurs numériques pour chaque étude. Quand la production de méthane a été mesurée, les résultats sont indiqués dans la colonne «Remarques».

\begin{tabular}{|c|c|c|c|c|}
\hline \multicolumn{2}{|c|}{ Extraits de Plantes } & Effets & Remarques & Références \\
\hline Ration Témoin & $+\mathrm{S}$. $\operatorname{rarak}(4 \mathrm{mg} / \mathrm{mL})$ & \multirow{3}{*}{$-20 \%(P<0,05)$} & \multirow{3}{*}{ in vitro } & \multirow{3}{*}{$\begin{array}{l}\text { Wina et al } \\
2005\end{array}$} \\
\hline \multicolumn{2}{|c|}{$\mu g$ ARN $/ m L$ contenu ruminal } & & & \\
\hline 3,12 & 2,61 & & & \\
\hline Ration Témoin & + Saponines de thé & \multirow{3}{*}{$=(P>0,05)$} & \multirow{3}{*}{$\begin{array}{c}\text { in vitro } \\
-27,7 \% \mathrm{CH}_{4} \mathrm{~L} / \mathrm{kg} \mathrm{MSI}\end{array}$} & \multirow{3}{*}{$\begin{array}{l}\text { Mao et al } \\
2010\end{array}$} \\
\hline \multicolumn{2}{|c|}{ \% rrs Bacteria } & & & \\
\hline 0,34 & 0,36 & & & \\
\hline Ration Témoin & + Saponines & \multirow{3}{*}{ De $-20 \%$ à $-78 \%$} & \multirow{3}{*}{$\begin{array}{c}\text { in vitro } \\
\text { Carduus }<\text { Knautia }< \\
\text { Trigonella. }<\text { Sesbania }{ }^{2}\end{array}$} & \multirow{3}{*}{$\begin{array}{c}\text { Goel et al } \\
2008 b\end{array}$} \\
\hline \multicolumn{2}{|c|}{ \% rrs Bacteria } & & & \\
\hline ND & ND & & & \\
\hline Ration Témoin & $+\mathrm{HE}^{1}$ & \multirow{3}{*}{$=(P>0,05)$} & \multirow{3}{*}{ in vivo } & \multirow{3}{*}{$\begin{array}{c}\text { Ohene-Adjei } \\
\text { et a/ } 2008\end{array}$} \\
\hline copies rrs Arch & a/ng ADN génomique & & & \\
\hline ND & ND & & & \\
\hline
\end{tabular}

1 HE : Huiles Essentielles.

2 Classement des différentes plantes utilisées dans l'étude en fonction de leur toxicité envers les Archaea méthanogènes.

ND : information non disponible dans la publication. 
d'autres, il était significativement réduit (Hristov et al 2003). Les effets sur la faune ruminale de tannins provenant d'une quinzaine d'arbres différents ont été testés in vitro; uniquement 3 des molécules étudiées ont présenté des activités inhibitrices (Monforte-Briceno et al 2005). Les mécanismes d'action des tannins sur les Archaea méthanogènes et en particulier M. ruminantium ont été étudiés par Tavendale et al (2005). Deux souches, YLM-1 et DSM1093 ont été cultivées sur un milieu contenant un extrait de tannins condensés. Les fractions oligomériques n'ont pas eu d'effet sur la production de $\mathrm{CH}_{4}$ par les deux souches. En revanche, la fraction polymérique a complètement inhibé la méthanogenèse. Pour la souche YLM-1, ces effets étaient uniquement bactériostatiques, et bactéricides pour la souche DSM1093 qui n'a pas repris ses activités métaboliques même après incubation prolongée. Les résultats de cette étude suggèrent que la baisse des émissions de $\mathrm{CH}_{4}$ observée avec des rations contenant des tannins (Patra et Saxena 2009, Martin et al 2010) peut être due à une inhibition directe des méthanogènes, qui dépendrait toutefois de la structure chimique des tannins condensés. Il est également nécessaire de mener des études à long terme pour s'assurer que des espèces résistantes de méthanogènes n'apparaîtront pas. Les bactéries tannins-tolérantes (genre Streptococcus) présentent un autre problème potentiel. La tolérance dans certains cas de figure est due à leur capacité à modifier ou dégrader les tannins (Smith et al 2005), ce qui permet d'éliminer les tannins du milieu ruminal.

\section{c) Les huiles essentielles}

Les huiles essentielles sont des liquides concentrés en composés aromatiques volatils obtenus par distillation ou extraction dans des solvants de plantes. Ces composés sont généralement abondants dans les herbes et les épices et à moindre degré chez les autres plantes, et ils jouent un rôle protecteur contre les attaques bactériennes, fongiques ou d'insectes. Les huiles essentielles sont lipophiles et interagissent avec les membranes cellulaires ce qui est à l'origine de leur toxicité et de leurs propriétés anti-microbiennes particulièrement à l'égard des bactéries à Gram positif. Des concentrations basses d'huiles essentielles $(<100 \mathrm{ppm})$ ont inhibé la croissance de presque toutes les cultures pures de bactéries du rumen (McIntosh et al 2003). Parmi elles, S. bovis s'est révélée être la souche la plus résistante ; la souche la plus sensible était $P$. ruminicola bien que finalement elle ait développé une résistance. En ce qui concerne le nombre de protozoaires, il n'est pas influencé (Benchaar et al 2008) ou diminue significativement (Ando et al 2003) avec l'ajout d'huiles essentielles dans la ration de bovins.

Très peu de données concernant les effets des huiles essentielles sur la population méthanogène sont disponibles dans la littérature et aucune étude n'a été réalisée in vivo. En culture, la croissance de $M$. smithii a été inhibée seulement avec une concentration en huiles supérieure à 1000 ppm (McIntosh et al 2003). Ohene-Adjei et al (2008) ont montré que la supplémentation de rations à base d'orge avec les huiles essentielles de cannelle, d'ail ou du genévrier n'a pas influencé le nombre des copies du gène rrs des Archaea quantifiées en qPCR (tableau 3). En revanche, le nombre des clones phylogénétiquement reliés aux Methanosphaera stadtmanae, M. smithii et à quelques taxa non cultivés avait augmenté aux dépens des clones apparentés à $M$. ruminantium. Dans l'étude in vitro d'Agarwal et al (2009), l'inclusion d'huile de menthe à hauteur de $0,33 \mathrm{~mL} / \mathrm{L}$ a multiplié par deux le nombre des méthanogènes, alors que la production de $\mathrm{CH}_{4}$ avait diminué de $20 \%$, sans affecter la concentration totale des AGV. Des doses plus fortes (1 et $2 \mathrm{~mL} / \mathrm{L}$ ) ont eu un effet toxique sur les Archaea s'accompagnant d'une baisse de la méthanogenèse. Les effets négatifs sur la production de $\mathrm{CH}_{4}$ à faibles doses peuvent être expliqués par l'apparition des espèces méthanogènes résistantes mais moins efficaces dans la production de $\mathrm{CH}_{4}$.

L'utilisation des extraits de plantes pour réduire la méthanogenèse est une piste intéressante par son caractère «naturel» apprécié par les consommateurs, mais aussi parce qu'elle est facilement applicable en pratique. Cependant, vu le nombre élevé de molécules potentiellement intéressantes et les réponses divergentes de l'écosystème microbien observées dans les différentes études, des recherches supplémentaires sont nécessaires pour identifier les meilleures cibles.

\section{4 / Composition de la ration}

\section{1 / Proportion et nature du concentré dans la ration}

Il est admis d'une manière générale que la production de $\mathrm{CH}_{4}\left(\mathrm{CH}_{4} \mathrm{~g} / \mathrm{kg}\right.$ de matière sèche ingérée) avec une ration riche en cellulose est plus importante qu'avec une ration riche en amidon (Doreau et al 2011). Or, les rations riches en amidon n'ont pas d'effet apparent sur le nombre des méthanogènes dans le rumen (tableau 4), bien que la diversité de ces microorganismes sem- ble être influencée par la composition de la ration (tableau 5). Les clades méthanogènes dominants restent toujours les mêmes quel que soit le régime (Wright et al 2004a, 2007), mais des différences au niveau espèce (ou souche) liées au changement alimentaire ont été rapportées (Zhou et al 2010). En comparaison avec des animaux recevant des rations riches en amidon, la diversité des méthanogènes est plus importante chez des ovins au pâturage (Wright et al 2004a). De même, la communauté méthanogène dans le rumen de bovins était plus riche et plus diverse chez des animaux recevant un concentré fibreux comparés à des animaux recevant un concentré riche en amidon et en lipides (Popova et al 2011). L'amidon et/ou les lipides exerceraient une pression sélective sur les méthanogènes du rumen (Popova et al 2011). Zhou et al (2010) ont suggéré que la ration sélectionnerait des voies méthanogènes particulières : avec des régimes pauvres en énergie (74\% paille d'avoine), les souches Methanobrevibacter ruminantium NT7 qui produisent du $\mathrm{CH}_{4}$ en réduisant le $\mathrm{CO}_{2}$ sont les plus abondantes. Leur proportion diminue, avec des régimes riches en céréales (28\% d'avoine et $58 \%$ d'orge), au profit des souches Methanobrevibacter smithii qui sont capables d'utiliser aussi le formate ou le méthanol (Zhou et al 2010). La sélection des méthanogènes serait réalisée en raison d'une moindre disponibilité du substrat $\mathrm{H}_{2}$, car avec des régimes riches en amidon, une réorientation des voies fermentaires vers la production de propionate aux dépens de l'acétate est souvent observée (Beauchemin et al 2009, Martin et al 2010). Dans ces conditions, la corrélation négative qui existe entre les productions de $\mathrm{CH}_{4}$ et de propionate signifie que moins d' $\mathrm{H}_{2}$ est formé par unité d'aliment (Janssen 2010). Comme toute règle, elle n'est pas sans exception : la production de $\mathrm{CH}_{4}$ peut diminuer avec des régimes riches en céréales sans que la proportion molaire du propionate change pour autant (Doreau et Dollé 2011). La réduction de la méthanogenèse serait alors la conséquence d'un effet direct de la baisse du $\mathrm{pH}$ ruminal sur les microorganismes du rumen, en particulier sur les protozoaires et les Archaea (Martin et al 2010).

La composition de la ration et la nature de l'aliment concentré influencent l'orientation des fermentations ruminales, mais aussi la diversité de la communauté des Archaea méthanogènes. Les réductions observées dans la méthanogenèse peuvent être dues à une moindre disponibilité de l'hydrogène et/ou une communauté méthanogène métaboliquement moins active. 
Tableau 4. Effets de la composition de la ration alimentaire sur la concentration des Archaea méthanogènes du rumen. Les différents modes d'expression de la concentration microbienne sont indiqués en italique au-dessus des valeurs numériques pour chaque étude. Quand la production de méthane a été mesurée, les résultats sont indiqués dans la colonne «Remarques». Toutes les études ont été réalisées in vivo sur des bovins, à l'exception de celle de Mao et al (2010) qui a été réalisée sur des agneaux en croissance.

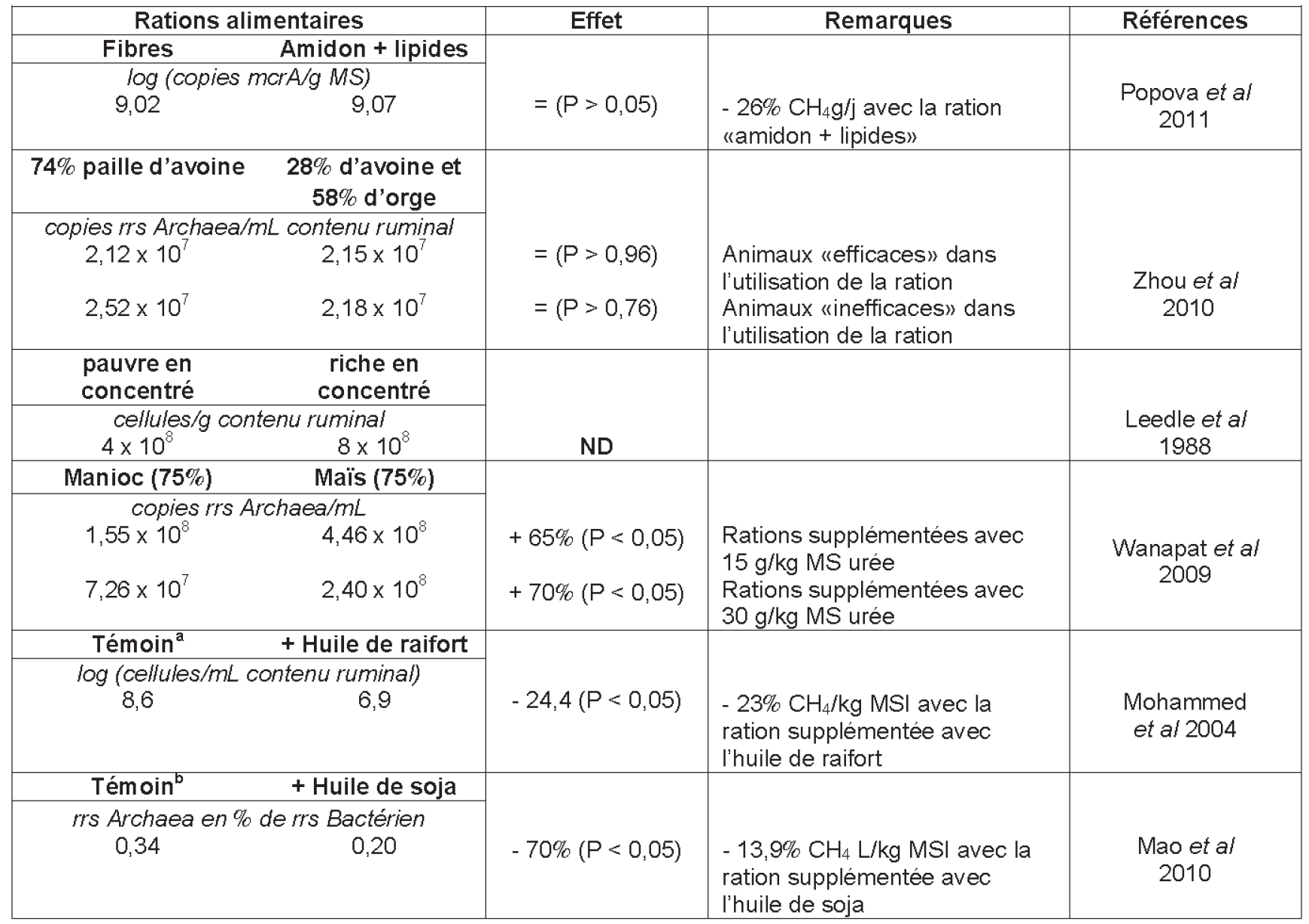

ND : information non disponible dans la publication.

a Ration témoin composée de fourrage : mélange d'aliments concentrés 60 : 40 ; la ration expérimentale est supplémentée avec $2 \%$ sur la base de la matière sèche ingérée d'huile de raifort.

b Ration témoin composée de fourrage : mélange d'aliments concentrés $60: 40$; la ration expérimentale est supplémentée avec 3\% sur la base de la matière sèche ingérée d'huile de soja.

\section{2 / Apport de lipides}

A la différence des régimes riches en amidon, la supplémentation de la ration avec des lipides a l'avantage d'augmenter sa valeur énergétique sans provoquer des baisses importantes du $\mathrm{pH}$ ruminal. La réduction des émissions de $\mathrm{CH}_{4}$ avec des rations supplémentées en lipides (Beauchemin et al 2009, Martin et al 2010) s'expliquerait également par une baisse dans l'activité métabolique des méthanogènes, conséquence de la disponibilité limitée du substrat $\mathrm{H}_{2}$ (Doreau et al 2011). Les lipides ont des effets toxiques sur les protozoaires (Doreau et Ferlay 1995), donc la disponibilité réduite de $1^{\prime} \mathrm{H}_{2}$ peut également être expliquée par une production d' $\mathrm{H}_{2}$ plus faible.

In vivo, l'huile de soja (administrée à hauteur de $3 \%$ de la matière sèche ingé- rée (MSI)) a diminué l'abondance relative des protozoaires de plus de $50 \%$ et a exercé un fort effet toxique sur les bactéries fibrolytiques $F$. succinogenes et $R$. flavefaciens, dont l'abondance relative (en \% de rss bactérien) a diminué de 30 et $80 \%$ respectivement (Mao et al 2010). En revanche, la supplémentation des rations de vaches laitières avec de l'huile de lin n'a pas eu d'effet sur les bactéries fibrolytiques $R$. albus et $R$. flavefaciens (Mosoni et al 2008). Le nombre des protozoaires n'a pas été affecté avant le repas, mais a diminué 2 heures plus tard, ce qui peut expliquer la baisse observée dans les émissions de $\mathrm{CH}_{4}$ par les animaux.

En ce qui concerne la population méthanogène, in vitro, dans l'étude de Dohme et al (2001) utilisant les fermenteurs RUSITEC, son nombre n'est pas affecté par l'ajout de $50 \mathrm{~g} / \mathrm{kg} \mathrm{MS}$ de substrat d'acides gras saturés à chaîne courte à longue $\left(\mathrm{C}_{8}: 0\right.$ à $\left.\mathrm{C}_{18}: 0\right)$; en revanche la population se trouve significativement réduite $(-78 \%)$ dans l'étude de Soliva et al (2003) avec l'ajout de l'acide laurique $\left(\mathrm{C}_{12}: 0 ; 30 \mathrm{mg} / 100 \mathrm{~mL}\right.$ contenu ruminal). Zhang et al (2008) ont observé une croissance de la population méthanogène avec des petites doses (35 g/kg MS de substrat ajouté) d'acides gras à chaîne longue saturés $\left(\mathrm{C}_{18: 0}\right)$ ou mono-insaturés $\left(\mathrm{C}_{18: 1}\right)$ et une inhibition par des faibles $(35 \mathrm{~g} / \mathrm{kg}$ MS substrat) et fortes ( $70 \mathrm{~g} / \mathrm{kg}$ MS substrat) doses d'acides gras à chaîne longue polyinsaturée $\left(\mathrm{C}_{18: 2}, \mathrm{C}_{18: 3}\right)$.

In vivo, la concentration des Archaea méthanogènes dans le liquide ruminal des animaux dépourvus de protozoaires était multipliée par 3 avec la supplémentation de la ration avec $50 \mathrm{~g} / \mathrm{kg}$ de MSI d'huile de coprah (Machmüller et 
Tableau 5. Effets de la composition de la ration alimentaire sur la diversité des Archaea méthanogènes du rumen. Toutes les études ont été réalisées in vivo sur des bovins.

\begin{tabular}{|c|c|c|c|c|}
\hline Ration & $\begin{array}{l}\text { Gène } \\
\text { ciblé }\end{array}$ & $\begin{array}{c}\text { Nombre de } \\
\text { bandes }^{a}\end{array}$ & Espèces identifiées & Références \\
\hline $\begin{array}{c}\text { Foin } \\
75 \% \text { orge }\end{array}$ & rrs & $\begin{array}{l}6 \text { à } 8 \\
1 \text { à } 4\end{array}$ & $\begin{array}{l}\text { Methanobrevibacter spp. } \\
\text { Methanosphaera stadmanae }\end{array}$ & $\begin{array}{l}\text { Ouwerkerk } \\
\text { et a/ } 2008\end{array}$ \\
\hline $\begin{array}{l}\text { Manioc (+ } 15 \text { ou } 30 \mathrm{~g} / \mathrm{kg} \mathrm{MS} \mathrm{urée)} \\
\text { Maïs (+ } 15 \text { ou } 30 \mathrm{~g} / \mathrm{kg} \mathrm{MS} \text { urée) }\end{array}$ & rrs & $\begin{array}{l}7 \\
7\end{array}$ & ND & $\begin{array}{l}\text { Wanapat } \\
\text { et a/ } 2009\end{array}$ \\
\hline $\begin{array}{l}74 \% \text { paille d'avoine } \\
28 \% \text { d'avoine et } 58 \% \text { d'orge }\end{array}$ & rrs & $\begin{array}{l}24 \\
22\end{array}$ & $\begin{array}{l}\text { Methanobrevibacter } \\
\text { ruminantium NT7 } \\
\text { Methanobrevibacter smithii } \\
\text { Methanobrevibacter sp. AbM4 } \\
\text { Methanobrevibacter } \\
\text { ruminantium NT7 }\end{array}$ & $\begin{array}{c}\text { Zhou } \\
\text { et al } 2010\end{array}$ \\
\hline $\begin{array}{l}87 \% \text { concentré riche en fibres } \\
87 \% \text { concentré riche en amidon + lipides }\end{array}$ & $m c r A$ & $\begin{array}{l}19 \\
14\end{array}$ & ND & $\begin{array}{l}\text { Popova } \\
\text { et al } 2011\end{array}$ \\
\hline
\end{tabular}

ND : information non disponible dans la publication.

a En utilisant les techniques d'empreinte moléculaire, les différents segments d'ADN sont visualisés sous forme de bandes. En général, on assume qu'une bande correspond à une seule séquence et donc à une espèce microbienne donnée. Le nombre des bandes est utilisé pour estimer la richesse de la population ciblée.

al 2003). A l'inverse un effet toxique marqué (-20\%) sur les Archaea a été rapporté chez des taurillons avec l'huile de raifort japonais supplémentée à hauteur de $20 \mathrm{~g} / \mathrm{kg}$ de MSI (Mohammed et al 2004, tableau 4). L'abondance relative des méthanogènes (en $\%$ du rrs bactérien) a baissé de $40 \%$ chez des agneaux quand la ration était supplémentée avec $30 \mathrm{~g} / \mathrm{kg}$ de MSI d'huile de soja (Mao et al 2010). La supplémentation de la ration avec de l'huile de lin n'a pas eu d'effet sur les Archaea méthanogènes chez des vaches laitières (Mosoni et al 2008).

De plus, la sensibilité des différents ordres de méthanogènes aux acides gras n'est pas la même. In vitro, avec un apport d'acide laurique (30 mg), le nombre des Methanococcales a régressé plus significativement que celui des Methanobacteriales, Methanosarcinales ou des Methanomicrobiales (Soliva et al 2003). En accord avec les essais in vitro, la supplémentation de la ration avec de l'huile de coprah (riche en acide laurique) chez des ovins défaunés, s'est accompagnée d'une baisse du signal de la sonde ciblant l'ARNr 16S des Methanococcales (Machmüller et al 2003). Les auteurs ont utilisé le nombre des copies de l'ARNr 16S en tant qu'indicateur de l'activité métabolique des Archaea, ce qui leur a permis de conclure que la baisse observée dans la quantité de $\mathrm{CH}_{4}$ produit $(-14 \%$ en $\mathrm{L} / \mathrm{kg}$ de matière organique digérée) était due à l'effet inhibiteur de l'huile sur les méthanogènes et en particulier sur les Methanococcales.

L'apport de lipides pour diminuer la méthanogenèse est une piste intéressante et facilement applicable en pratique. Les études menées jusqu'à présent indiquent une sensibilité différente des méthanogènes en fonction de la nature et/ou la quantité du supplément lipidique. Cet élément sera à considérer pour choisir les molécules les mieux adaptées et efficaces à long terme.

\section{Conclusion}

La production de $\mathrm{CH}_{4}$ est une voie métabolique essentielle assurant la continuité des fermentations ruminales. La thermodynamique des processus métaboliques intervenant dans la dégradation des aliments dans le rumen est fortement dépendante de la production et de l'utilisation de $\mathrm{l}^{\prime} \mathrm{H}_{2}$. Dans le cas particulier de la méthanogenèse, l'absence de lien entre la production de $\mathrm{CH}_{4}$ et le nombre de méthanogènes semble aujourd'hui établie, sauf lorsque des inhibiteurs spécifiques des Archaea sont employés (vaccin, additifs chimiques). Cette synthèse met en évidence que les variations dans la production de $\mathrm{CH}_{4}$ observées suite à des modifications de l'écosystème microbien ou d'un des constituants de la ration, s'expliquent par des changements de diversité et/ou d'activité des Archaea en raison d'une moindre disponibilité en $\mathrm{H}_{2}$. La diversité des méthanogènes dans le rumen est encore mal connue, et de nouvelles séquences, appartenant au phylum sans représentants cultivés, sont constamment découvertes. Bien qu'a priori très peu de genres soient présents dans le rumen, cette communauté se caractérise par un fort potentiel d'adaptation. Comme dans tout écosystème, les actions ciblant des micro-organismes particuliers sollicitent inévitablement des réponses des autres populations présentes. Ceci souligne la nécessité d'évaluer toutes les stratégies pour réduire la production de $\mathrm{CH}_{4}$ entérique sur le long terme et en considérant la communauté microbienne du rumen dans son ensemble. 


\section{Références}

Agarwal N., Shekhar C., Kumar R., Chaudhary L.C., Kamra, D.N., 2009. Effect of peppermint (Mentha piperita) oil on in vitro methanogenesis and fermentation of feed with buffalo rumen liquor. Anim. Feed Sci. Tech., $148,321-327$

Ando S., Nishida T., Ishida M., Hosoda K., Bayaru E., 2003. Effect of peppermint feeding on the digestibility, ruminal fermentation and protozoa. Livest. Prod. Sci., 82, 245-248

Balch W.E., Fox G.E., Magrum L.J., Woese C.R., Wolfe R.S., 1979. Methanogens: reevaluation of a unique biological group. Microbiol. Mol. Biol. Rev., 43, 260-296.

Beauchemin K.A., McAllister T.A., McGinn S.M., 2009. Dietary mitigation of enteric methane from cattle. $\mathrm{CAB}$ Reviews: Perspectives in Agric. Vet. Sci. Nutr. Nat. Res., CABI, Wallingford, Royaume-Uni, 4, 1-18.

Benchaar C., McAllister T.A., Chouinard P.Y., 2008. Digestion, ruminal fermentation, ciliate protozoal populations, and milk production from dairy cows fed cinnamaldehyde, quebracho condensed tannin, or Yucca schidigera saponin extracts. J. Dairy Sci., 91, 4765-4777.

Chaucheyras-Durand F., Durand H., 2010. Probiotics in animal nutrition and health Benef. Microbes, 1, 3-9.

Chaucheyras F., Fonty G., Bertin G., Gouet P., 1995. In vitro $\mathrm{H}_{2}$ utilization by a ruminal acetogenic bacterium cultivated alone or in association with an archaea methanogen is stimulated by a probiotic strain of Saccharomyces cerevisiae. Appl. Environ. Microbiol., 61, 3466-3467.

Chaucheyras-Durand F., Walker N.D., Bach A., 2008. Effects of active dry yeasts on the rumen microbial ecosystem: Past, present and future. Anim. Feed Sci. Technol., 145, 5-26.

Chung Y.H., Walker N.D., McGinn S.M., Beauchemin K.A., 2011. Differing effects of 2 active dried yeast (Saccharomyces cerevisiae) strains on ruminal acidosis and methane production in nonlactating dairy cows. J. Dairy Sci., 94, 2431-2439.

Cook S.R., Maiti P.K., Chaves A.V., Benchaar C., Beauchemin K.A., McAllister T.A., 2008. Avian (IgY) anti-methanogen antibodies for reducing ruminal methane production: in vitro assessment of their effects. Austr. J. Exp. Agric., 48, 260-264.

Czerkawski J.W., 1986. An introduction to rumen studies. Pergamon Press (Ed.), Oxford, England, 236p.

Denman S.E., Tomkins N.W., McSweeney C.S., 2007. Quantitation and diversity analysis of ruminal methanogenic populations in response to the antimethanogenic compound bromochloromethane. FEMS Microbiol. Ecol., $62,313-322$

Dohme F., Machmüller A., Wasserfallen A., Kreuzer M., 2001. Ruminal methanogenesis as influenced by individual fatty acids supplemented to complete ruminant diets. Lett. Appl. Microbiol., 32, 47-51.

Doreau M., Dollé J.B., 2011. Strategies for reducing greenhouse gas emissions in dairy production. A European perspective. Proc. Eastern Nutr. Conf., Montréal, Canada, 12-13.
Doreau M., Ferlay A., 1995. Effect of dietary lipids on nitrogen metabolism in the rumen a review. Livest. Prod. Sci., 43, 97-110.

Doreau M., Martin C., Eugène M., Popova M., Morgavi D.P., 2011. Leviers d'action pour réduire la production de méthane entérique pa les ruminants. In: Gaz à effet de serre en élevage bovin : le méthane. Doreau M., Baumont R., Perez J.M. (Eds). Dossier, INRA Prod. Anim. 24, 461-474.

Edwards J.E., McEwan N.R., Travis A.J., John Wallace R., 2004. 16S rDNA librarybased analysis of ruminal bacterial diversity. Antonie Van Leeuwenhoek, 86, 263-281.

Eugène M., Archimède H., Sauvant D. 2004. Quantitative meta-analysis on the effects of defaunation of the rumen on growth, intake and digestion in ruminants. Livest. Prod. Sci. $85,81-97$

Fonty G., Joblin K., Chavarot M., Roux R., Naylor G., Michallon F., 2007. Establishment and development of ruminal hydrogenotroph in methanogen-free lambs. Appl. Environ. Microbiol., 73, 6391-6403.

Garcia J.L., Patel B.K.C., Ollivier B., 2000 Taxonomic, phylogenetic, and ecological diversity of methanogenic archaea. Anaerobe $6,205-226$

Gill M., Smith P., Wilkinson J.M., 2010. Mitigating climate change: the role of domestic livestock. Animal, 4, 323-333.

Goel G., Makkar H.P.S., Becker K., 2008 Effects of Sesbania sesban and Carduus pycnocephalus leaves and Fenugreek (Trigonella foenum-graecum L.) seeds and their extracts on partitioning of nutrients from roughage- an concentrate-based feeds to methane. Anim. Feed Sci. Technol., 147, 72-89.

Goel G., Makkar H.P.S., Becker K., 2009 Inhibition of methanogens by bromochloromethane: effects on microbial communities and rumen fermentation using batch and continuous fermentations. Brit. J. Nutr. 101, 1484-1492.

Guo Y.Q., Liu J.X., Zhu W.Y., McSweeney C., 2007. Shifts of rumen microbial population detected by real-time PCR when methanogenesis is inhibited. J. Anim. Feed Sci., 16, 107-112.

Guo Y.Q., Liu J.X., Lu Y., Zhu W.Y, Denman S.E., McSweeney C.S., 2008. Effect of tea saponin on methanogenesis, microbia community structure and expression of mcrA gene, in cultures of rumen microorganisms. Lett. Appl. Microbiol., 47, 421-426.

Hess H.D., Kreuzer M., Díaz T.E., Lascano C.E., Carulla J.E., Soliva C.R., Machmüller, A., 2003. Saponin rich tropical fruits affect fermentation and methanogenesis in faunated and defaunated rumen fluid. Anim. Feed Sci. Technol., 109, 79-94

Hristov A.N., McAllister T.A., Van Herk F.H. Cheng K.J., Newbold C.J., Cheeke P.R 1999. Effect of Yucca schidigera on ruminal fermentation and nutrient digestion in heifers. J. Anim. Sci., 77, 2554-2563.

Hristov A.N., Ivan M., Neill L., McAlliste T.A., 2003. Evaluation of several potential bioactive agents for reducing protozoal activity in vitro. Anim. Feed Sci. Technol., 105, 163-184.

Hvelplund T., 1991. Volatile fatty acids an protein production in the rumen. In: Rumen microbial metabolism and ruminant digestion. Jouany J.P. (Ed). INRA, Paris, France, 165-178.

Janssen P.H., 2010. Influence of hydrogen on rumen methane formation and fermentation balances through microbial growth kinetics and fermentation thermodynamics. Anim. Feed Sci. Technol., 160, 1-22.

Janssen P.H., Kirs M., 2008. Structure of the archaeal community of the rumen. Appl Environ. Microbiol., 74, 3619-3625.

Jarvis G.N., Strömpl C., Burgess D.M., Skillman L.C., Moore E.R.B., Joblin K.N., 2000. Isolation and identification of ruminal methanogens from grazing cattle. Curr. Microbiol., 40, 327-332.

Jeyanathan J., Kirs M., Ronimus R.S., Hoskin S.O., Janssen P.H., 2011. Methanogen community structure in the rumens of farmed sheep, cattle and red deer fed different diets. FEMS Microbiol. Ecol., 76, 311-326.

Johnson K.A., Johnson D.E., 1995. Methane emissions from cattle. J. Anim. Sci., 73, 2483 2492.

Jouany J.P., 1994. Les fermentations dans le rumen et leur optimisation. INRA Prod. Anim. 7, 207-225.

Jouany J.P., Morgavi D.P., 2007. Use of "natural" products as alternatives to antibiotic feed additives in ruminant production. Animal 1, 1443-1466.

Jouany J.P., Thivend P., 2008. La production de méthane d'origine digestive chez les ruminants et son impact sur le réchauffement climatique. Manag. Avenir, 20, 259-274.

Karnati S.K.R., Yu Z., Sylvester J.T., Dehority B.A., Morrison M., Firkins J.L., 2003. Technical note: Specific PCR amplification of protozoal 18S rDNA sequences from DNA extracted from ruminal samples of cows. J. Anim. Sci., 81, 812-815.

Kim M., Morrison M., Yu Z., 2011. Status of the phylogenetic diversity census of ruminal microbiomes. FEMS Microbiol. Ecol., 76, 4963.

Knight T., Ronimus R.S., Dey D., Tootill C., Naylor G., Evans P., Molano G., Smith A., Tavendale M., Pinares-Patino C.S., Clark H., 2011., Chloroform decreases rumen methanogenesis and methanogen populations without altering rumen function in cattle. Anim. Feed Sci. Technol., 166, 101-112.

Lana R.P., Russell J.B., Van Amburgh M.E., 1998. The role of $\mathrm{pH}$ in regulating ruminal methane and ammonia production. J. Anim. Sci., 76, 2190-2196.

Leedle J.A., Greening R.C., 1988. Postprandial changes in methanogenic and acidogenic bacteria in the rumens of steers fed high- or low-forage diets once daily. Appl. Env. Microbiol., 54, 502-506

Lin C., Raskin L., Stahl D.A., 1997. Microbial community structure in gastrointestinal tracts of domestic animals: comparative analyses using rRNA-targeted oligonucleotide probes. FEMS Microbiol. Ecol., 22, 281-294.

Liu Y., Whitman W.B., 2008. Metabolic, phylogenetic, and ecological diversity of the methanogenic archaea. Ann. N.Y. Acad. Sci. $1125,171-189$ 
Machmüller A., Soliva Carla R., Michael K. 2003. Effect of coconut oil and defaunation treatment on methanogenesis in sheep. Reprod. Nutr. Dev., 43, 41-55.

Mao H.L., Wang J.K., Zhou Y.Y., Liu J.X. 2010. Effects of addition of tea saponins and soybean oil on methane production, fermentation and microbial population in the rumen of growing lambs. Livest. Sci., 129, 56-62.

Martin C., Morgavi D.P., Doreau M., 2010 Methane mitigation in ruminants: from microbe to the farm scale. Animal, 4, 351-365.

McGinn S.M., Beauchemin K.A., Coates T., Colombatto D., 2004. Methane emissions from beef cattle: Effects of monensin, sunflower oil, enzymes, yeast, and fumaric acid. J. Anim. Sci., 82, 3346-3356.

McIntosh F.M., Williams P., Losa R., Wallace R.J., Beever D.A., Newbold C.J., 2003. Effects of essential oils on ruminal microorganisms and their protein metabolism. Appl. Environ. Microbiol., 69, 5011-5014.

Miller T.L., Lin C., 2002. Description of Methanobrevibacter gottschalkii sp. nov., Methanobrevibacter thaueri sp. nov., Methanobrevibacter woesei sp. nov. and Methanobrevibacter wolinii sp. nov. Int. J. Syst. Evol. Microbiol., 52, 819-822.

Miller T.L., Wolin M.J., 1985. Methanosphaera stadtmaniae gen. nov., sp. nov.: a species that forms methane by reducing methanol with hydrogen. Arch. Microbiol., $141,116-122$

Mohammed N., Ajisaka N., Lila Z.A., Hara K., Mikuni K., Hara K., Kanda S., Itabashi H., 2004. Effect of Japanese horseradish oil on methane production and ruminal fermentation in vitro and in steers. J. Anim. Sci., 82, 1839-1846.

Monforte-Briceno G.E., Sandoval-Castro C.A., Ramirez-Aviles L., Capetillo Leal C.M., 2005. Defaunating capacity of tropical fodder trees: Effects of polyethylene glycol and its relationship to in vitro gas production. Anim. Feed Sci. Technol., 123, 313-327.

Morgavi D.P., Forano E., Martin C. Newbold C.J., 2010. Microbial ecosystem and methanogenesis in ruminants. Animal, 4, 10241036.

Morvan B., Dore J., Rieu-Lesme F., Foucat L., Fonty G., Gouet P., 1994. Establishment of hydrogen-utilizing bacteria in the rumen of the newborn lamb. FEMS Microbiol. Lett., 117, 249-256.

Mosoni P., Rochette Y., Graviou D., Martin C., Forano E., Morgavi D.P., 2008. Influence of protozoa on the number of cellulolytic bacteria and methanogens in the rumen of sheep evaluated by qPCR. $6^{\text {th }}$ INRA RRI Symp. Gut Microb., Clermont-Ferrand, France, 46p.

Mosoni P., Martin C., Forano E., Morgavi D.P., 2011. Long-term defaunation increases the abundance of cellulolytic ruminococci and methanogens but does not affect the bacterial and methanogen diversity in the rumen of sheep. J. Anim. Sci., 89, 783-791.

Moss A.R., Jouany J.P., Newbold J., 2000. Methane production by ruminants: its contribution to global warming. Ann. Zootech., 49, 231-253.

Newbold C.J., Lassalas B., Jouany J.P., 1995. The importance of methanogens associated with ciliate protozoa in ruminal methane production in vitro. Lett. Appl. Microbiol., 21, 230-234.
Newbold C.J., El Hassan S.M., Wang J., Ortega M.E., Wallace R.J., 1997. Influence of foliage from African multipurpose trees on activity of rumen protozoa and bacteria. Brit. J. Nutr., 78, 237-249.

Newbold C.J., Lopez S., Nelson N., Ouda J.O., Wallace R.J., Moss A.R., 2005. Propionate precursors and other metabolic intermediates as possible alternative electron acceptors to methanogenesis in ruminal fermentation in vitro. Brit. J. Nutr., 94, 27 35.

Newbold C.J., Rode L.M., 2006. Dietary additives to control methanogenesis in the rumen. Soliva C.R., Takahashi J., Kreuzer M (Eds). Elsevier Int. Congr. Series 1293 , Elsevier, Amsterdam, Pays-Bas, Proc. Greenhouse Gases Anim. Agric., 138-147.

Nicholson M.J., Evans P.N., Joblin K.N., 2007. Analysis of methanogen diversity in the rumen using temporal temperature gradient gel electrophoresis: identification of uncultured methanogens. Microb. Ecol., 54, 141-150.

Nolan J.V., Hegarty R.S., Hegarty J., Godwin I.R., Woodgate R., 2010. Effects of dietary nitrate on fermentation, methane production and digesta kinetics in sheep. Anim. Prod. Sci., 50, 801-806.

Ohene-Adjei S., Chaves A.V., McAllister T.A., Benchaar C., Teather R.M., Forster R.J., 2008. Evidence of increased diversity of methanogenic archaea with plant extract supplementation. Microb. Ecol., 56, 234-242.

Ouwerkerk D, Turner A.F., Klieve A.V., 2008. Diversity of methanogens in ruminants in Queensland. Austr. J. Exp. Agric., 48, 722-725.

Ozutsumi Y., Tajima K., Takenaka A., Itabashi H., 2005. The effect of protozoa on the composition of rumen bacteria in cattle using 16S rRNA gene clone libraries. Biosci. Biotechnol. Biochem., 69, 499-506.

Ozutsumi,Y., Tajima K., Takenaka A., Itabashi H., 2006. Real-Time PCR detection of the effects of protozoa on rumen bacteria in cattle. Curr. Microbiol., 52, 158-162.

Patra A., Saxena J., 2009. Dietary phytochemicals as rumen modifiers: a review of the effects on microbial populations. Antonie Van Leeuwenhoek, 96, 363-375.

Pelmont J., 2005. Hydrogène - Acétate Méthane. In: Biodégradations et métabolismes, collection Grenoble Sciences, 197-244.

Popova M., 2011. Structure et activité de la communauté des Archaea méthanogènes dans le rumen en relation avec la production de méthane par les ruminants. Thèse de l'Université Blaise Pascal, Clermont-FerrandTheix, France, 264p.

Popova M., Martin C., Rochette Y., Graviou D., Morgavi D.P., 2010. Methane emissions and rumen methanogens in sheep harbouring or not protozoa. Proc. Joint Symp. RRI-INRA Gut Microbiology: new insights into gut microbial ecosystems, Aberdeen, UK.

Popova M., Martin C., Eugène M., Mialon M.M., Doreau M., Morgavi D.P., 2011. Diet composition influences methanogenic archaea diversity and activity in the rumen of feedlot bulls. Anim. Feed Sci. Technol., 166, 113-121.

Regensbogenova M., Pristas P., Javorsky P., Moon-van der Staay S.Y., Van Der Staay G.W.M., Hackstein J.H.P., Newbold C.J., McEwan N.R., 2004. Assessment of ciliates in the sheep rumen by DGGE. Lett. Appl. Microbiol., 39, 144-147.

Sadet S., Martin C., Meunier B., Morgavi D.P., 2007. PCR-DGGE analysis reveals a distinct diversity in the bacterial population attached to the rumen epithelium. Animal 1, 939-944.

Sar C., Santoso B., Mwenya B., Gamo Y., Kobayashi T., Morikawa R., Kimura K., Mizukoshi H., Takahashi J., 2004. Manipulation of rumen methanogenesis by the combination of nitrate with $\beta$ 1-4 galactooligosaccharides or nisin in sheep. Anim. Feed Sci. Technol., 115, 129-142.

Sharp R., Ziemer C.J., Stern M.D., Stahl D.A., 1998. Taxon-specific associations between protozoal and methanogen populations in the rumen and a model rumen system. FEMS Microbiol. Ecol., 26, 71-78.

Shin E.C., Cho K.M., Lim W.J., Hong S.Y., An C.L., Kim E.J., KimY.K., Choi B.R., An J.M., Kang J.M., Kim H., Yun H.D., 2004. Phylogenetic analysis of protozoa in the rumen contents of cow based on the 18S rDNA sequences. J. Appl. Microbiol., 97, 378-383.

Smith A.H., Zoetendal E., Mackie R.I., 2005. Bacterial mechanisms to overcome inhibitory effects of dietary tannins. Microb. Ecol., 50, 197-205.

Soliva C.R., Hindrichsen I.K., Meile L., Kreuzer M., Machmuller A., 2003. Effects of mixtures of lauric and myristic acid on rumen methanogens and methanogenesis in vitro. Lett. Appl. Microbiol., 37, 35-39.

Stumm C.K., Gijzen H.J., Vogels G.D., 1982. Association of methanogenic bacteria with ovine rumen ciliates. Brit. J. Nutr., 47, 95-99.

Takenaka A., Itabashi H., 1995. Changes in the population of some functional groups of rumen bacteria including methanogenic bacteria by changing the rumen ciliates in calves. $\mathrm{J}$ Gen. Appl. Microbiol., 41, 377-387.

Tavendale M.H., Meagher L.P., Pacheco D., Walker N., Attwood G.T., Sivakumarab S., 2005. Methane production from in vitro rumen incubations with Lotus pedunculatus and Medicago sativa, and effects of extractable condensed tannin fractions on methanogenesis. Anim. Feed Sci. Technol., 123-124, 403-419.

Tokura M., Ushida K., Miyazaki K., Kojima Y., 1997. Methanogens associated with rumen ciliates. FEMS Microbiol. Ecol., 22, 137-143.

Ungerfeld E.M., Rust S., Boone, D., Liu Y., 2004. Effects of several inhibitors on pure cultures of ruminal methanogens. J. Appl. Microbiol., 97, 520-526.

Ungerfeld E.M., Kohn R.A., Wallace R.J., Newbold C.J., 2007. A meta-analysis of fumarate effects on methane production in ruminal batch cultures. J. Anim. Sci., 85, 25562563.

Van Kessel J.A.S., Russell J.B., 1996. The effect of $\mathrm{pH}$ on ruminal methanogenesis. FEMS Microbiol. Ecol., 20, 205-210.

Vermorel M., Jouany J.P. Eugène M., Sauvant D., Noblet J., Dourmad J.Y., 2008. Evaluation quantitative des émissions de méthane entérique par les animaux d'élevage en 2007 en France. INRA Prod. Anim., 21, 403-418.

Wallace R.J., Newbold C.J., 1993. Rumen fermentation and its manipulation: the development of yeast cultures as feed additives. In: 
Biotechnology in the feed industry. Lyons T.P. (Ed) Alltech Technical Publications, Nicholasville, Kentucky, 173-192.

Wanapat M., Pilajun R., Kongmun P., 2009 Ruminal ecology of swamp buffalo as influenced by dietary sources. Anim. Feed Sci. Technol., 151, 205-214.

Weimer P.J., Waghorn G.C., Odt C.L., Mertens D.R., 1999. Effect of diet on populations of three species of ruminal cellulolytic bacteria in lactating dairy cows. J. Dairy Sci., $82,122-134$

Welkie D.G., Stevenson D.M., Weimer P.J., 2010. ARISA analysis of ruminal bacterial community dynamics in lactating dairy cows during the feeding cycle. Anaerobe, 16, 94100 .

Whitford M.F, Teather R.M., Forster R.J., 2001. Phylogenetic analysis of methanogens from the bovine rumen. BMC Microbiology, 1,5 .

Williams Y.J., Popovski S., Rea S.M., Skillman L.C., Toovey A.F., Northwood K.S., Wright A.D.G., 2009. A vaccine against rumen methanogens can alter the composition of archaeal populations. Appl. Env. Microbiol., $75,1860-1866$.
Wina E., Muetzel S., Hoffmann E., Makka H.P.S., Becker K., 2005. Saponins containing methanol extract of Sapindus rarak affect microbial fermentation, microbial activity and microbial community structure in vitro. Anim. Feed Sci. Technol., 121, 159-174.

Woese C.R., Kandler O., Wheelis M.L., 1990. Towards a natural system of organisms: proposal for the domains Archaea, Bacteria and Eucarya. Proc. Nat. Acad. Sci. U.S.A., 87, 4576-4579.

Wright A.D.G., Williams A.J., Winder B., Christophersen C.T., Rodgers S.L., Smith K.D., 2004a. Molecular diversity of rumen methanogens from sheep in Western Australia. Appl. Environ. Microbiol., 70, 1263-1270.

Wright A.D.G., Kennedy P., O'Neill C.J., Toovey A.F., Popovski S., Rea S.M., Pimm C.L., Klein L., 2004b. Reducing methane emissions in sheep by immunization against rumen methanogens. Vaccine, 22, 3976-3985.

Wright A.D., Auckland C.H., Lynn D.H. 2007. Molecular Diversity of methanogens in feedlot cattle from Ontario and Prince Edward Island, Canada. Appl. Environ. Microbiol., 73 , 4206-4210

Yanagita K., Kamagata Y., Kawaharasaki M., Suzuki T., Nakamura Y., Minato H., 2000.
Phylogenetic analysis of methanogens in sheep rumen ecosystem and detection of methanomicrobium mobile by fluorescence in situ hybridization. Biosci. Biotechnol. Biochem., 64, 1737-1742.

Zhang C.M., Guo Y.Q., Yuan Z.P., Wu Y.M., Wang J.K., Liu J.X., Zhu W.Y., 2008. Effect of octadeca carbon fatty acids on microbial fermentation, methanogenesis and microbial flora in vitro. Anim. Feed Sci. Technol., 146, 259269

Zhou M., Hernandez-Sanabria E., Guan L.L., 2010. Characterization of variation in rumen methanogenic communities under different dietary and host feed efficiency conditions, as determined by PCR-denaturing gradient gel electrophoresis analysis. Appl. Env. Microbiol., 76, 3776-3786.

Zijderveld S.M., Gerrits W.J.J., Apajalaht J.A., Newbold J.R., Dijkstra J., Leng R.A. Perdok H.B., 2010. Nitrate and sulfate: Effective alternative hydrogen sinks for mitigation of ruminal methane production in sheep. J. Dairy Sci., 93, 5856-5866.

Zijderveld S.M., Gerrits W.J.J., Dijkstra J., Newbold J.R., Hulshof R.B. A., Perdok H.B., 2011. Persistency of methane mitigation by dietary nitrate supplementation in dairy cows. J. Dairy Sci., 94,4028-4038.

\section{Résumé}

Le méthane entérique est formé par les Archea méthanogènes au cours de la dégradation microbienne des aliments dans le rumen, ce qui implique que toute variation dans sa production est le résultat d'un changement dans la chaîne alimentaire microbienne. En effet la structure et/ou l'activité de la communauté microbienne fermentaire (bactéries et protozoaires) détermine la quantité et, partiellement, l'utilisation de l'hydrogène, substrat limitant de la méthanogenèse. Les microorganismes méthanogènes ne constituent qu'une petite partie de la biomasse et de la diversité microbienne dans le rumen. Aujourd'hui, l'absence de lien entre la production de méthane et le nombre des méthanogènes est bien établie sauf lorsque des inhibiteurs spécifiques des Archaea sont employés (vaccin, additifs chimiques). Les variations dans la production de méthane, observées suite à des modifications de l'écosystème microbien ou d'un des constituants de la ration, s'expliquent par des changements de diversité et/ou d'activité des Archaea par suite d'une moindre disponibilité en hydrogène. En effet, les études récentes relient les variations observées dans la production de méthane à des variations dans l'activité métabolique des méthanogènes et/ou à des changements fins dans leur diversité au niveau de l'espèce ou même de la souche. Ainsi, le développement des stratégies efficaces à long terme pour réduire les émissions de méthane, implique inévitablement la bonne compréhension des mécanismes impliqués en considérant l'écosystème microbien dans son ensemble.

\section{Abstract}

\section{Methane production and ruminal microbial interactions}

Enteric methane is formed during the microbial degradation of food in the rumen, and any variation in its production level is the result of a change in the microbial ecosystem. Indeed the structure and / or activity of the microbial community determine the production and, partially, the utilization of dihydrogen (the limiting substrate of methanogenesis). Methane is produced by a specialized group of microbes, the methanogens that represent only a small part of the microbial biomass and diversity in the rumen. There is no relationship between methane production and number of methanogens except where specific inhibitors of $A r c h a e a$ are used (vaccines, chemical additives); new studies suggest that the variations in methane production are more likely due to changes in the metabolic activity of methanogens and / or changes in their diversity at the species or even strain level. The development of long-term mitigation strategies requires a good understanding of the mechanisms involved in methanogenesis and needs to consider the microbial ecosystem as a whole.

POPOVA M., MORGAVI D.-P., DOREAU M., MARTIN C., 2011. Production de méthane et interactions microbiennes dans le rumen. In : Gaz à effet de serre en élevage bovin : le méthane. Doreau M., Baumont R., Perez J.M. (Eds). Dossier, INRA Prod. Anim. 24, 447-460 